\title{
THE EFFECTS OF CEREBRAL DESTRUCTION UPON HABIT-FORMATION AND RETENTION IN THE ALBINO RAT
}

\author{
K. S. LASHLEY AND S. I. FRANZ \\ Department of Psychology of the Johns Hopkins University and the Government \\ Hospital for the Insane

\section{INTRODUCTION}

It has long been known that the cerebrum is anatomically complex and it is recognized that its functions are diverse. There is also the appreciation of the failure to correlate the known anatomical facts with the functional observations. There are many reasons for the last. The variation in cerebral structure in different species of animals is one of the greatest of the difficulties in the correlation of the anatomical and the functional, for two animals with obviously dissimilar brain structures may appear in the main to be functionally similar, and conversely two animals with obviously dissimilar activities may have quite similar cerebral structural arrangements. The diversity of structures in the same brain has been more recently emphasized. Differences in the arrangements or in the method of combination of cells and fibers have been described as points of major importance, and many cortical areas, a score or more, have been described as different organs. They have also been assumed to represent equal functional differences. On the functional side, especially when man has been under consideration, the diversity has been exaggerated, and this has probably been carried over into modern neurology from the mental faculty aspect of Gall's phrenological system, although the anatomical part of Gall's work is totally discarded. The differences of emotions, hate, joy, fear, anger, of sensations such as color, tone, and the taste and smell qualities, of movement and of will, of desire, of interest, and of all mental states, have led to assump- 
tions of uniqueness by the uncritical in psychological analysis. There followed the further belief that each one of the supposedly different mental states must have a corresponding anatomically distinct counterpart.

When these beliefs are looked at critically they are recognized to be logical from the standpoint of any of the current brainmind hypotheses. But this logical conclusion applies only to the general and not to the particular way in which the differences are looked at. It is doubtless true that there are many arrangements of cells and fibers in different parts of the cortex, and these differences in arrangement may mean differences in function. That great differences in function are not necessary consequences of anatomical differences may be illustrated, but of course not proven, by an analogy. It is well recognized that a house may be built of wood, or of bricks, or of stone, and that it may be one or two or more stories in height, be narrow or broad, or with large windows and doors, or with Venetian blinds, or painted blue, or with a gable roof, or with any other characteristics. But, whatever these anatomical characteristics may be the structure remains a place of habitation. The differences in structure do not indicate fundamental functional differences of the collections, they are modifications of only certain minor elements, and point only to minor functional differences. The function of the habitation may, therefore, differ slightly because of its combinations of internal and external structures, for it may be more comfortable in winter, or be conducive to cleanliness, or the reverse. It still remains a house with the general functions which all such structures have. The windows let in light, the doors permit entry and exit, the walls protect, and the furnishings give comfort, to different degrees, but the same general functions pertain to the cottage, to the mansion and to the apartment house. The functional similarities are more pronounced than the structural differences.

Equally with mental states and the cerebral anatomical structures. We may discover by careful analysis that although the mental states differ they are not so divergent as a superficial observation would indicate. There are many similarities, many 
common elements, in apparently dissimilar mental conditions. We also find that the cerebral structures do not differ widely in fundamentals. Many of the cells have the same general mass and appearance, but in one place may differ in number from those in another location. Their staining qualities are similar, the neurofibrils are much the same, the most marked differences are the direction and the length of the axones and the number of collaterals. Consequently, it should be obvious that great care should be taken that points of minor difference are not made the basis for major deductions.

At the same time care should be exercised that apparent similarities are not accepted as equalities and that a certain condition should not too hastily be assumed to point exclusively to one explanation. But this mistake is one of the most common in dealing with cerebral functions. Von Monakow has emphasized the distinctions which must be made in certain cases, and has pointed out some of the difficulties of interpretation. In one direction these difficulties are to be appreciated by the careful consideration of the temporary and the residual defects following a cerebral accident. But there are many more. For example, after the destruction of certain parts of the cerebrum of an animal, if a beam of light is thrown into the eye, or if an object crosses the visual field, and the eyes turn in the proper direction one cannot be certain whether the animal sees or the reaction is a reflex without vision.

For cases such as that just mentioned we have a means of more exact determination. 'This is the method of training which can be used both prior and subsequent to any experimental destructions. We may set such conditions to an operated animal which exhibits a reaction to light stimuli that the animal will be able to form a habit provided the cerebral sensory, associational (if they exist), and motor elements be intact. If a necessary part of the sensory-motor mechanism be out of order such a habit can not be aicquired. By varying the end conditions, either the sensory or the motor or both, it is possible to deduce the effects of destructions if they be more than temporary, and only in this way is it possible to determine accu- 
rately the character of a certain loss. Such a defect might apparently be motor. If this should be so we have reason to believe that a required movement could not be initiated from the cerebrum by any form of stimulus, whether light or sound or touch. If, however, the defect be sensory, let us say visual, the problem changes. A stimulus of that particular kind would not serve to produce a habit of any character, whereas other sensory stimuli (sound, touch, smell, etc.) could be used as the means to produce habits. By changing the conditions both on the sensory and motor sides it is also possible to discover what may be termed an "association" loss, although this is in some particulars more difficult than the sensory and motor losses.

After a cerebral accident in man there is also the possibility of determining the degree of retention, the characters of the retained habits, and the capability of formation of new habitual modes of reaction, i.e., behavior. In the clinical examinations of man chief, and frequently exclusive, use is made of the speech habits, although the exclusive employment of speech as the mode of reaction has certain disadvantages. They are not always obvious and they appear to be little appreciated. One of these is that an inability may be reported by speech which by other means it is possible to discover does not exist. This fact is recognized in certain well developed cases which in the past have been called hysterical. It is now admitted that in many other individuals similar "hysterical" symptoms may exist without there being easily recognized signs. Diverse mental states, such as dementia, great joy, or even a lack of understanding, may result in variations in speech habits which mask other effects. This being so, it is clear that to accept as final evidence of a defect a negation (by speech) is similar to the conclusion that an animal sees if the eyes are turned towards the stimulating light. The experimental method should be extended and the habit reaction method especially should be applied to the determination of defects in man after cerebral lesions. The limitation of clinical studies on cerebral functions to the consideration of speech reactions as the motor side of learned reactions can in many cases result only in superficial 
knowledge. The adoption of methods looking toward the determination of other habit forms will result in more complete information.

Although it is commonly believed that habit formation is due to the functioning of cerebral parts, and especially those parts which are called cortical, it is by no means right to conclude that all habit reactions are due to cerebral, or more restrictedly cortical, activities. Leaving aside those reactions which must pass by way of subsidiary stations, like the thalamus, as part of the total reaction, it is doubtless the case that certain habits are carried out by the exclusive use of non-cortical, and exclusively also perhaps by non-cerebral parts. This is shown in the reactions of the so-called lower animals, and it has been contended that for the execution of some long-established habits in higher animals only non-cerebral parts are needed. There is reason to believe that in the brainless frog certain simple habits may be acquired. One of the urgent needs at the present time both in neurology and in the study of learning is the establishment of the parts played by the different portions of the nervous system. With these facts in hand it will not only be possible to understand something of learning and forgetting, but at the same time we shall be better able to appreciate that inadequately named condition which is called cerebral vicarious functioning.

Two main problems were in mind when the following work was begun. One was the effects of different lesions upon habit formation and retention, the second was the determination of the parts needed for habit formation. These problems are identical in some particulars, but they can also be considered to be independent. It may be that in a normal animal a habit is formed by the interaction of certain nervous elements, but that when any of these elements have been destroyed or even interfered with other elements may take their places. Or, it may be that in the process of learning many different elements are used at first, but that the number decreases as the habit is acquired.

The scope of the experiments described here has been limited to a determination of the relation of the frontal pole and dorsal 
convexity of the cerebrum to the formation and retention of habits which involve chiefly responses to tactile and kinesthetic stimulation. After operation to destroy the frontal pole of both hemispheres (section III) or the entire dorsal convexity of the cortex (section V) the animals were trained on the inclined-plane box or maze and their rate of learning was compared with that of normal individuals. In other experiments (sections I, II, and IV) normal animals were trained upon the same problems and after the destruction of various areas of the cortex were tested to determine the degree of retention of the habits previously established and their ability to reform the habits in the cases where these had been lost.

In the carrying out of the operative procedures excessive hemorrhage was not infrequently encountered. To avoid this as much as possible the operations were performed rapidly. The sizes of the brain and skull are such that there is no space for packing to check a hemorrhage, and it was thought best to operate quickly even if some animals died because of the resulting hemorrhage from the cerebral lesion, rather than have an equal or greater number of deaths from hemorrhage from the longitudinal sinus. This was possible because of the number of animals which were available. Most of the cerebral operations were carried out through small skull openings, and partly because of this the lesions differed in all cases. Slightly different positions of the heads of two animals make the views of the small operative fields dissimilar, variations in the sharpness of the section knife make distinct variations in the ease, depth and completeness of the intended sections, and even slight variations in the relations of the brain to the skull sutures give difficulties that are not easily overcome. The complete removal of the top of the skull and the consequent full view of the superior surface of the brain would have been a more satisfactory procedure in some ways. The difficulty of controlling the hemorrhage from the skull is however added to the difficulty of controlling the hemorrhage from the cerebral section. At the same time even though the top part of the skull be removed without any ill effect other difficulties persist. The point of insertion of 
the knife can be more accurately determined, but slight variations cannot be avoided and these would make the lesions dissimilar. In addition, the quantity and the extent of the hemorrhage cannot be controlled, and this hemorrhage acts as a superimposed lesion. In some cases the lateral ventricles were found to be filled with blood, and in other cases clots were found at the base and even at the cerebro-cerebellar junction. Mention may also be made here of the variations in the location of the stimulable areas (the motor areas), report of which will later be made by one of us (L). Whatever operative technique is used the destructions are varying, and the most that can be expected in these small animals is to operate on sufficient numbers, and to select and compare those cases which have relatively similar lesions. This we have done. In all cases the lesions will be described and the comparison of sets of animals will be made.

When the experimental part of the work was completed the animals were killed and their brains were removed, fixed in 10 per cent formaldehyde, dehydrated, and cut in celloidin. Horizontal sections $80 \mu$. in thickness were cut and every tenth section was stained in toluidin blue and mounted in balsam. Each brain was given an arbitrary number and the examination and description of the lesions were made without knowledge of the behavior data, except in the case of the extensive lesions which were recognizable in the sections.

For reconstruction of the lesions serial outline sketches of the sections were made under the projection microscope to show the extent of the lesion visible under low powers of the microscope. The sections were then examined under higher power and the parts which seemed certainly involved in the lesion, either through actual destruction of the cortex or severance from all connection with the descending fiber tracts, were filled in on the sketches. The plane of the sections was determined for each brain by reference to the corpora quadrigemina and knee of the corpus callosum, measurements of the extent of the lesion were made, and these were reduced to the dimensions of the diagram used in case the brain varied from the average. Finally the extent of the lesion was marked on the diagram in the planes of the sections and the areas so outlined were blocked in. 
The brains were first turned over to a technician to be sectioned. As a result two brains were lost and several others so badly prepared that accurate reconstructions were impossible. Six brains were sectioned by the technician, the remainder by one of the writers. In the descriptions of the lesions reference is made to well defined land-marks, particularly the limits of the ventricles, the divisions of the corpus callosum, the gyrus hippocampus, and the subcortical ganglia. The relative positions of these structures are shown in the serial sections, figured in plate I, figure 22 .

I. THE RETENTION OF A SIMPLE KINESTHETIC-MOTOR HेABIT AFTER DESTRUCTION OF THE FRONTAL POLE OF THE CORTEX

In experiments described earlier (1) a number of animals were trained in the simple maze (fig. 1). An attempt was then

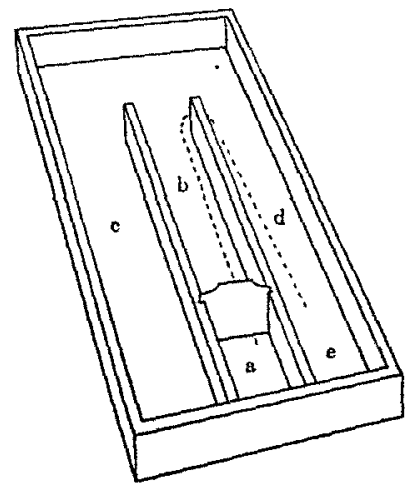

Fig, 1. The Simple Maze

$a$, starting compartment; $b$, middle alley; $c, c u l d e s a c ; d$, alley leading to food.

made to destroy the frontal portion of the cortex by transverse incisions through small openings in the parietal bones and as soon as the animals had recovered sufficiently from the operation, usually within forty-eight hours, they were tested for retention of the habit. In thirteen of the fourteen animals that survived the operation there was demonstrated some reten- 
tion of the habit, evidenced either by relatively few errors in the first trials of the retention tests or by survival of individual peculiarities of reaction to the maze. Details of these experiments have been given in the earlier paper. The extent of the cerebral lesion has now been determined for each animal and a report of the findings will be given in the first section of this paper.

The experiments are here given the same numbers as in the first article and page references for each experiment are given to facilitate reference to the original description. A brief estimate of the degree of retention is included for each animal with the record of the total number of errors made during the first fifteen trials of training and the first fifteen of the retention tests. This is followed by the description of the lesions.

In the diagrams prepared for this section of the paper we have figured only so much of the lesion as is obvious, either from the total separation of the injured parts from the remainder of the brain, the complete degeneration of the cortex, or the unmistakable section of the descending tracts. In every case it is probable that the lesion affected a much more extensive area than that indicated but it has seemed best to restrict the description to the obvious destructions.

After certain of the animals (experiments 8, 9, 10,11, 12 and 13) had recovered from the effects of the operation and had given evidence of the retention of the habit a second operation, designed to destroy the temporal or occipital regions, was performed. The description of the second lesion is included with that of the first, in the animals which survived; the effects of the operation will be described in experiment 15 .

Experiment 1 (page 8). Almost perfect retention. Errors: learning 5 , retention 1 .

Lesion (plate II, fig. 1). There is a transverse cut extending diagonally across both cerebral lobes. From above the knee of the corpus callosum on each side it passes out along the forceps of the callosum to the external capsule and thence to the cortex, $1.5 \mathrm{~mm}$. behind the base of the olfactory bulb. Below, on the left, the lesion extends to the floor of the lateral ventricle, on 
the right to the base of the lobe behind the olfactory bulb. Practically all the cortex of both hemispheres lying in front of the knee of the corpus callosum is destroyed by the lesion.

Experiment 2 (page 8). Partial retention. Errors: learning 8 , retention 2 .

Lesion. Not enough sections of the brain were preserved for an accurate determination of the extent of injury. Apparently the lesion was superficial, extending over the antero-dorsal surface of the frontal poles.

Experiment 3 (page 9). Partial retention. Errors: learning 2 , retention 4. Secondary evidence of retention.

Lesion (plate II, fig. 3). The brain was imperfectly sectioned. Right hemisphere. There is a transverse section of the hemisphere just in front of the forceps of the corpus callosum, extending from the inner margin of the mesial cortex through the lateral cortex. Left hemisphere. The lesion is similar to that on the right but involves the mesial cortex as well.

The post rior extent of the lesion could not be determined accurately. The destruction was certainly not less than that shown in the figure.

Experiment 4 (page 9). Partial retention. Errors: learning 21 , retention 2 .

Lesion (plate II, fig. 4). Right hemisphere. There is a complete transection of the anterior pole in a vertical plane passing through the knee of the corpus callosum. Left hemisphere. The cut is in the same plane as that on the right but penetrates only from the mesial surface to the external capsule and ventrad to the fibers of the peduncle.

Experiment 5 (page 10). Perfect retention. Errors: learning 19 , retention 2 .

Lesion (plate II, fig. 5). Right hemisphere. There is a small injury on the mesial surface above the knee of the corpus callosum. Left hemisphere. There is a small cylindrical cyst extending from the dorsal cortex through the knee of the corpus callosum and the cercbral peduncle, severing the fibers coming from the frontal pole.

Experiment 6 (page 10). Perfect retention. Errors: learning 7 , retention 0 . 
Lesion (plate II, fig. 6). The operation was by a single median opening. There is an extensive destruction of cortex at the opening in the skull and a transverse cut extending ventrad from it past the knee of the corpus callosum, destroying all the cortex lying between and in front of the forceps of the callosum.

Experiment 7 (page 11). Retention nearly perfect. Errors: learning 11 , retention 1 .

Lesion (plate II, fig. 7). Right hemisphere.' There is a transverse cut extending forward from over the knee of the corpus callosum, through the forceps to the fibers of the peduncle. There is a large cyst in the mesial cortex of the frontal pole. The destruction is probably limited to the dorso-medial surfaces of the lobe. Left hemisphere. The Jesion extends from the tip of the frontal pole along the course of the fibers to the end of the forceps, then turns laterad along the external capsule for a short distance and finally out along the course of the radial fibers to the cortex.

Experiment 8 (page 11). Partial retention. Frors: learning 7 , retention 3 . The brain was so damaged in sectioning that nothing could be made of the extent of the lesion.

Experiment 9 (page 12). Nearly perfect retention. Errors: learning 23 , retention 2 .

Lesion (plate II, fig. 9). Right hemisphere. There is a section of the hemisphere from above the knee of the corpus callosum diagonally forward to the base of the olfactory bulb. The lesion is superficial, destroying chiefly the mesial cortex in front of the callosum and above the olfactory tracts. Left hemisphere. There is a complete transverse section similar to that on the right but extending around onto the orbital surface.

Experiment 10 (page 12). Nearly perfect retention. Errors: learning 33 , retention 2 .

Lesion (plate II, fig. 10). Right hemisphere. First operation. There is a transverse incision extending ventrad in a plane passing through the end of the forceps of the corpus callosum to the base of the olfactory bulb, destroying all the frontal pole, which is filled by a large cyst, and cutting a part of the olfactory tract. Second operation. There is a small incision extending down 
from the dorsal convexity through the fornix and internal capsule and penetrating the thalamus in the region of the lateral thalamic nucleus. Left hemisphere. First operation. The lesion is similarly placed to that on the right but more superficial, passing just under the cortex through the end of the forceps to the base of the olfactory bulb. It narrows at the base and does not involve the olfactory tracts. The entire pole exclusive of the mesial cortex is destroyed, however. Second operation. There is a transverse lesion extending down from the dorsal convexity just in front of the hippocampus, cutting through the fornix and penetrating the crux cerebri for one half its width.

Experiment 11 (page 12). Perfect retention. Errors: learning 11 , retention 1 .

Lesion (plate II, fig. 11). Right hemisphere. First operation. There is a transverse section of the hemisphere just back of the knee of the corpus callosum and extending diagonally laterad to the cortex along the forceps of the callosum and ventrad to the floor of the lateral ventricle. The ventricle is distended until it occupies one-third of the width of the hemisphere. Second operation. There is a superficial incision extending fromabove the anterior end of the lateral ventricle to the posterior border of the corpus callosum and laterad along the external capsule to the level of the thalamus. There is a large cyst replacing the fibers of the external capsule in the occipital lobe. Left hemisphere. First operation. There is a transverse lesion just behind the knee of the corpus callosum extending downward to the level of the fornix. Internally it extends deeper, pentrating the olfactory fibers in the region of the anterior olfactory nucleus. Second operation. There is an incision passing in from the cortex to the external capsule near the posterior limit of the first lesion, thence extending backward along the external capsule for an indeterminate distance. The external capsule is largely replaced by a cyst extending into the occipital pole. The frontal poles of both hemispheres were completely severed from the rest of the brain by the first operation.

Experiment 12 (page 12). Retention perfect. Errors: learning 2 , retention 0 . 
Lesion (plate II, fig. 12). Right hemisphere. First operation. There is a transverse incision just in front of the forceps of the corpus callosum severing all of the anterior pole, except the mesial cortex, down to the olfactory tracts. Second operation. There is a lesion over the dorsal and orbital surfaces with completely degnerated cortex in the regions indicated in the figure. Left hemisphere. First operation. There is a lesion extending from the end of the forceps of the corpus callosum to the mesial cortex and ventrad into the olfactory fiber tracts. All of the mesial cortex anterior to the knee of the callosum is destroyed but little injury has been done to that of the lateral face of the anterior pole. Second operation. There is a lesion over the dorsal and orbital surfaces of the hemisphere extending along the fibers of the external capsule orer the area indicated, with complete degeneration of the overlying cortex.

Experiment 13 (page 12). Retention nearly perfect. Errors: learning 3 , retention 0 .

Lesion (plate II, fig. 13). Right hemisphere. First operation. There is a complete transverse section of the anterior pole through the end of the forceps of the corpus callosum to the level of the olfactory tracts. Second operation. There is a lesion extending from the first backward along the external capsule to the posterior border of the hippocampus, narrowing forward below at the level of the lateral ventricle. All the cortex overlying the lesion is completely degenerated. Left hemisphere. First operation. Transverse section of the anterior pole extending downward to just above the level of the olfactory tracts. Second operation. There is a longitudinal incision extending backward in the external capsule from the first lesion to the posterior edge of the hippocampus, covering the entire orbital surface down to the olfactory cortical funiculus. All the overlying cortex is degenerated.

Experiment 14 (page 13). No retention. The animal developed hemiparesis and was stuporous.

Lesion. An invasion of the thalamus by an extensive clot was determined by gross dissection.

Of the fourteen animals described in this series thirteen gave 
some evidence of the retention of the habit. An exact estimation of the individual degree of retention is precluded by the simplicity of the habit and the different extents to which the animals showed shock effects of the operation. Since all the animals with lesions restricted to the frontal regions retained the habit wholly or in part and since the lesions were for the most part incomplete the first question that arises is whether or not any particular area in the frontal region was left intact in all the animals. The combined extents of the lesions in this series are shown in figure 2. The entire frontal pole of each hemisphere extending down to the olfactory tracts was destroyed in one or another of the animals. No one part of the frontal pole remained undestroyed in all. It seems, then, that no particular part of the frontal pole of the rat's cortex is necessary for the

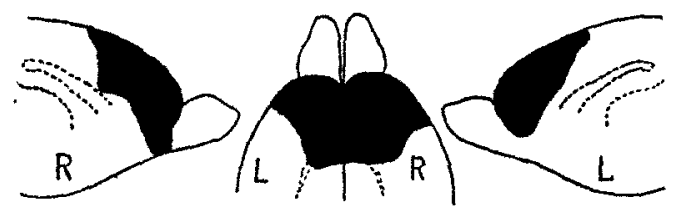

Fig. 2. Total Extent of Injuries to Cortex in Animals Descriaed in Series I

All parts of the cortex anterior to the knee of the corpus callosum have been destroyed.

retention of the maze-habit; there is no specialized region concerned with the maze-habit which has a uniform position for all animals. Furthermore, in some of the animals (experiments $1,3,4,10$ and 11), there was an almost complete destruction of all the cortex above and in front of the knee of the corpus callosum so that it seems very probable that no part of the frontal region of the rat's brain is concerned with the retention of the maze-habit.

A number of attempts have been made to find some correlation between the extent of lesion in these cases and the accuracy of performance in the retention tests but no such correlation seems to exist. Both animals with extensive and those with . slight lesions made perfect records in the retention tests 
and others with almost identical lesions made several errors. This lack of relation between the extent of frontal lesion and the degree of retention provides further evidence that the functioning of the maze-habit is independent of the frontal region of the cortex.

II. THE RETENTION OF THE MAZE-HABIT AFTER FRONTAL AND TEMPORAL OR FRONTAL AND OCCIPITAL LESIONS

Experiment 15. After retention had been tested in the animals described in experiments $8,9,10,11,12$ and 13 they were allowed to rest for two weeks and then were retrained for twenty-five trials, showing practically no loss of the habit in this time. They were next subjected to a second operation. In three, an incision was made from the locus of the first operation backward

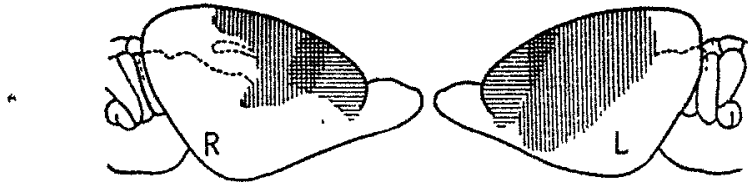

Fig. 3. Total Extent of the Lestons in Antmals of Series II, Which Retained the Maze-Habit After the Second Operation

on both sides for a distance of $5 \mathrm{~mm}$. In the other three the scalpel was passed almost horizontally backward through the cortex of the dorsal convexity from the region of the first lesion to the tentorium. Three of these animals survived, one after occipital lesion (11) and two after temporal lesion (10 and 12). The lesions have been defined in the descriptions of these animals and figured in plate II, figures 10, 11, and 12. The combined extent of the lesions is shown in figure 3 .

All three animals showed perfect retention of the habit after the second operation. They were each given fifteen trials in the maze on the day following the second operation, and ten trials on the second day. Number 10 averaged 2.5 seconds per trial in these twenty-five trials and made only one error. Number 12 averaged 2.6 seconds and made one error in the same number 
of trials. Number 11 was slower and required an average of 9.0 seconds per trial but did not make a single error or react in any way to the entrance to the cul de sac in twenty-five trials.

After the frst_operation all these animals had shown a perfect retention of the habit, in spite of a practically complete destruction of the frontal poles of both hemispheres. The second operation probably did little additional harm to number 10 beyond cutting the fimbria on both sides. In number 12 , however, large areas on the dorsal and orbital surfaces of both hemispheres were destroyed. In number 11 practically all the dorsal and lateral surfaces of the cortex overlying the gyri hippocampi and between them and the frontal poles was destroyed.

The effects of the first operation, taken in conjunction with the other experiments of the same series, indicate rather clearly that the persistence of the habit was not conditioned by the functional integrity of the frontal pole. The second operation resulted in the elimination of not less than half of the cortex of the dorsal convexity and the combined destruction resulting from all the operations performed on these animals, certainly includes not less than two thirds of the cortex, leaving only the occipital regions, the ventral surface, and the gyri hippocampi intact. We are justified in concluding therefore that no part of the cortex in front of the caudal end of the corpus callosum and above the level of the floor of the lateral ventricles is concerned with the retention of simple kinesthetic-motor habits.

\section{Experiments with the inclined-plane box}

The simple maze offered some disadvantages for a study of retention owing to the fact that it did not require a reaction that was sufficiently well defined to be certainly recognizable in the retention tests. It seemed best therefore to use some more complex habit in the later experiments for the sake of getting a more clearly defined series of activities and also with the possibility that the more complex habit, involving different types of reaction, might reveal a selective effect of the cerebral lesion upon certain types of activity. The inclined-plane box (2) was 
finally selected as combining a fairly specific reaction to a definite series of stimulating objects with relatively complex kinesthetic-motor habits. In order to complicate the kinesthetic habits somewhat and allow of greater individual variation than is possible in the usual type of this problem-box, the design shown in figure 4 was adopted. The problem-box consists of a wire covered rectangular frame-work having a door $(D)$, held open by a pair of flat brass springs, compressed between the door

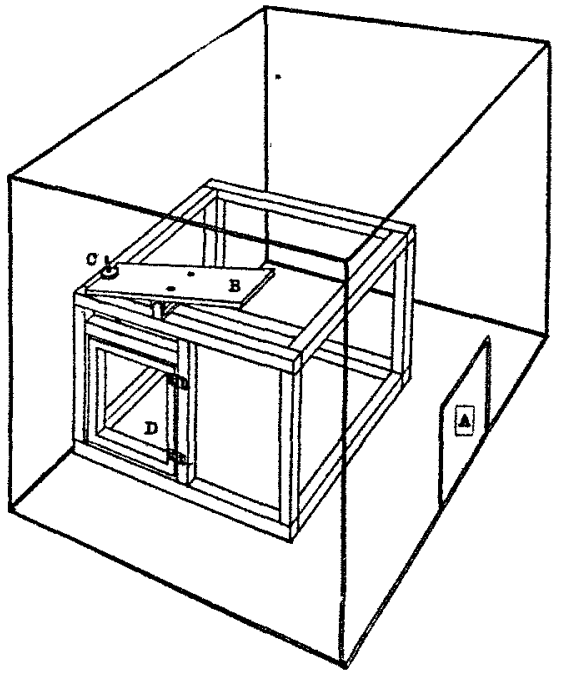

Fig. 4. The Incuined Plane Box

$A$, door of restraining cage; $B$, inclined plane; $C$, catch extending down to upper edge of door, $D$, door leading into food-box.

and its frame. On top of the box, above the door is a board $(B)$, supported in the middle by a metal fulcrum and weighted so that the end $C$ is slightly heavier than the other. From the board an adjustable metal rod $(C)$ extends through the top of the box to the door and serves as a latch to hold it closed. A pressure of from 50 to 75 grams at the free end of the plane $(B)$ is required to tilt it and release the door. This, the foodbox, is enclosed in a larger restraining cage having a door at $A$ and is pushed against the side of the restraining cage opposite 
the door so that only three sides are exposed. The animal, introduced into the restraining cage through the door $(A)$ must climb to the top of the food-box, push down the outer end of the plane $(B)$ for a distance of half an inch until the door springs open, then climb down and enter the door to get food. A momentary pressure is not sufficient to depress the plane and the animal must maintain the full pressure while the plane is moving down. The fact that he must climb upon the food-box makes possible a variety of ways of approaching the plane and the development of individual peculiarities of reaction.

The methods of training were those generally employed in experiments with similar apparatus. The animals, unless much weakened by loss of blood, were fed only in the food-box after the conclusion of the day's tests. Five trials were given daily.

Records were made for each trial of the time required by the animals to reach and push down the plane, and separate records of the time taken in going from the plane to the food after the plane had been tripped. Extensive notes were made of individual peculiarities in the path followed to the plane, of the method of pushing it down, and of the path followed from the plane to the food.

III. THE RATE OF LEARNING AFTER INJURY TO THE FRONTAL POLE

Experiment 16 As a preliminary test of the ability of the animals to form complex habits after the destruction of the frontal pole of the cortex a group of six animals which had been used to experiments on the maze (experiments 1, 2, 3, 4, 6 and 7) and had fully recovered from the operation was trained on the inclined plane, described and figured above. Their behavior when placed in the restaining cage was in all respects normal and they learned the problem at a practically normal rate. Their rate of improvement in the average time required for tripping the latch is compared in figure 5 with that of an equal number of normal animals trained under identical conditions. The actual time consumed in learning was somewhat less than that required by normal animals; their methods of learning were the 
same and their final efficiency was as great as that of any normals. Their quicker time on the first trials is probably due to the fact that they had been handled a great deal and were more accustomed to the experimenter than were the normal animals.

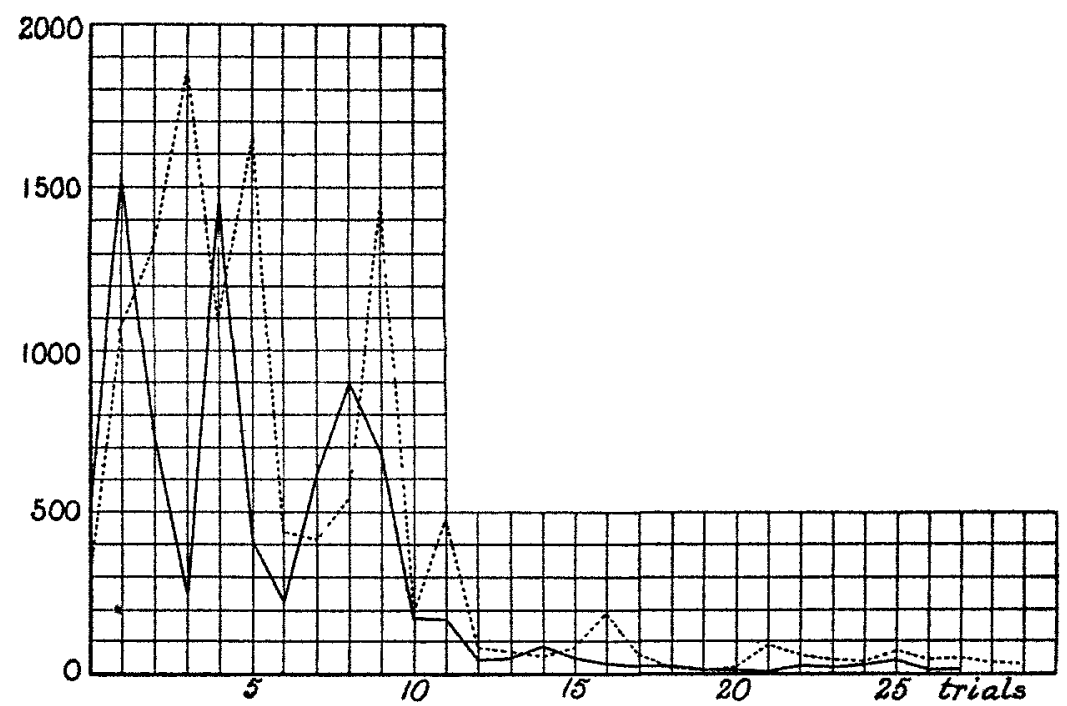

Fig. 5. A Comparison. of the Rate of Learning the Inclined Plane Box by Normal Animals and by Animals Afrter Injury to the Frontal Areas

Six animals are included in each group. The average time in seconds per trial is plotted. Normal rats: ...... Operated rats:

The extent of the lesions in these animals is shown in plate II, figures 1, 3, 4, 6 and 7. The combined extent of the lesion is shown in figure 6. Practically every part of the anterior pole of the cortex in front of the knee of the corpus callosum

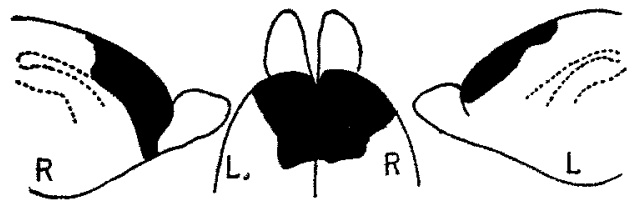

Fig. 6. Total Extent of Lesions in animals Which Learned the Inclined Plane Box after Operation 
was destroyed in one or another of these animals without interfering in any way with the formation of the relatively complex habit. In numbers 3,6 and 7 the lesions were small but in numbers 1 and 4 there was a loss of practically the entire frontal pole of both hemispheres without a correlated reduction of the learning ability.

It seems quite certain, therefore, that no particular part of the anterior third of the cortex of the white rat is necessary for the formation of a complex kinesthetic-motor habit and, from the condition in numbers 1 and 4, that the entire frontal region of the cortex may be dispensed with without any reduction of the ability to learn.

\section{RETENTION OF THE INCLINED-PLANE HABIT AFTER CEREBRAL LESIONS}

Earlier experiments with the higher mammals indicate that learning may take place in the absence of parts of the cortex which are normally functional in habit formation. Thus, Franz-(3) has found that the destruction of the frontal lobes in the cat and monkey is followed by the loss of recently formed habits but that the habits can be immediately reacquired and that the rate of learning is practically the same as before the loss of these areas. The ability of the animals described in series III to learn the inclined plane problem does not, therefore, preclude the possibility that the frontal region of the cortex is normally functional when present. To test this a series of normal animals were trained on the inclined plane box, then operated upon to destory the frontal areas, and tested for retention of the habit. Seventeen animals survived the operation and were tested thoroughly for retention or relearning of the habit.

In three animals the lesions were restricted to the dorsal and temporal regions, first to test the relation of these parts to the functioning of the habit, second, as a control of the effects of operative shock.

No final criterion of learning was adopted, but the animals 
were not operated upon until they had several times tripped the plane and gone to the food without excess movements. This required from 25 to 45 trials. A part were overtrained for a time about equal to that required for learning, receiving a total of from 75 to 115 trials.

\section{Operation without injury to the brain}

Experiment 17. Two trephine holes were made in the skull of an old female just back of the fronto-parietal suture and these were enlarged with bone forceps to a diameter of about $5 \mathrm{~mm}$. on either side. The scalp was then sewn up without further injury to the brain than was necessary in making the openings. In training the animal had been given 100 trials on the inclined box. Her average time per trial was for the first five trials; to plane, 1025 seconds; to door, 26 seconds. For the last five trials the averages were: to plane, 9.4 seconds; to door, 2.0 seconds.

Retention was tested on the second day after the operation. The average time per trial was: to plane, 46 seconds; to door, 9.2 seconds. Her reactions were unhesitating. The path followed from the door to the plane was direct and the plane was the only object in the restraining cage which excited more than a momentary reaction. In every trial the animal sprung the plane by standing beside it and pushing down upon its outer end with her fore feet. The slight increase in time over the last trials preceding the operation is due to a slower rate of movement and not to any increase of exploratory movements.

Autopsy showed small adhesions of the convexity of the hemispheres at the region of the trephine openings. The extent of the lesions is shown in plate III, figure 17.

After opening of the skull and exposure of an area of the cortex as great as that involved in the greater number of the experiments here described, this animal showed perfect retention. 


\section{Temporal lobes destroyed}

Experiment 18. A large opening, 2 by $5 \mathrm{~mm}$. was made on each side of the skull just back of the fronto-parietal suture of a medium sized female rat, 140 days old. Through these the scalpel was passed to destroy the temporal lobes. The animal had been trained on the inclined-plane box for 115 trials. The average time per trial for the first five trials was: to plane, 2719 seconds; to door, 61 seconds. That for the last five trials was: to plane, 34 seconds; to door, 2.2 seconds.

Retention was tested on the second day after the operation, when the animal was active and in good condition. The average time for the nine trials given on this day was: to plane, 22 seconds; to door, 11 seconds. Her specific reactions were wholly confined to the plane and door. On different trials she approached the plane from different directions, but always tripped it in the same way, by pushing down on its outer end with her fore feet, and in every trial except the first she went directly from the plane to the door of the food-box.

Extent of lesions (plate III, fig. 18). Right hemisphere. There is a large lesion on the dorsal convexity including almost all the cortex dorsal and lateral to the gyrus hippocampus, extending from near the longitudinal fissure, over the convexity and down over the temporal lobe to the level of the posterior horn of the lateral ventricle, following the course of the external capsule.

Left hemisphere. The lesion on the dorsal convexity is similar to that on the right. It extends downward around the antero-lateral face of the gyrus hippocampus and thence forward through the lateral face of the corpus striatum.

After a bilateral lesion destroying most of the cortex lying dorsad and laterad to the gyri hippocampi the motor habit previously established was retained.

Experiment 19. In the skull of a small female, 148 days old, two trephine holes were made about three millimeters back of the fronto-parietal suture. The scalpel was passed back from these to destroy the temporal lobes. The animal had been 
trained on the inclined-plane box for 75 trials. The average time per trial for the first five trials of learning was: to plane, 916 seconds; to door, 85 seconds. The average for the last five trials was: to plane, 2.8 seconds, to door, 2.2 seconds.

Retention was tested on the second day after the operation. At this time the animal was active and showed no abnormal symptoms. She was given ten trials on this day with the following average time per trial: to plane, 51 seconds; to door, 14 seconds.

The animal's behavior toward the problem box was in all respects normal. Her exploratory movements were restricted to the plane and in seven of the trials she tripped the eatch by pushing the plane down with her fore feet, a stereotyped method which she used before the operation.

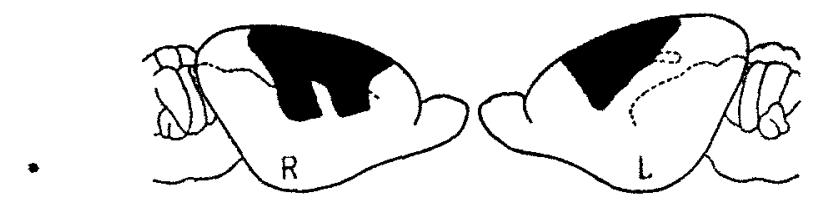

Fig. 7. Total Extent of Lesions in the Control Animals (Experiments 17,18 and 19)

Lesion (plate III, fig. 19). Right hemisphere. There is an extensive lesion of the cortex extending from the anterior border of the hippocampus to the knee of the corpus callosum and narrowing rapidly as it extends laterad on the orbital surface. It is continued over the orbital surface as a lesion of the external capsule around the upper half of the corpus striatum with degeneration of the overlying cortex.

Left hemisphere. There is a lesion similar to that on the right over the dorsal convexity but it is broader over the temporal region and extends downward only to the upper level of the lateral ventricle.

This animal, after the destruction of the cortex over the temporal and a portion of the orbital surface of both hemispheres, showed no deterioration of the habit previously formed.

The perfect retention of the habit by these three animals 
shows that any loss of the habit shown in other animals is probably not the result of operative shock but must be ascribed to the actual brain injury acting either locally in the operative field or extending by hemorrhage or intracranial pressure to other regions. The extensive destruction of the temporal surfaces of the cortex in experiments 18 and 19 shows that these areas play no important part in the retention of the habit. Figure 7 shows the combined extent of the lesions in these animals.

Frontal region destroyed: animals showing retention after operation

Experiment 20. Two trephine holes were made through the calvarium of a large female rat, 140 days old, and a transverse incision was made through the frontal pole of each hemisphere. The animal had been trained for 35 trials on the inclined plane box. The average time required for the first five trials was: to plane, 123 seconds; to door, 42 seconds. The average time required for the last five trials was: to plane, 13 seconds; to door, 3 seconds.

Retention was tested twenty-four hours after the operation but the animal was stuporous and did not react to the problem box. On the following day she opened the food-box three times. Her movements were slow and much time was spent in scratching at the dressing on her scalp. There were, however, few random movements and except for the diversions incident to this scratching, she kept closely to the direct path from the door to the plane and from the plane to the food. Her method of tripping the catch before the operation had been to walk to the back of the plane and, standing either on or beside it with her hind feet, to reach out to its outer end with her fore feet and push down, gradually throwing her weight forward on her fore feet. This same method was used throughout the trials following the operation, but the movements involved were carried out with greater inaccuracy than before. In some trials she went from the plane to the door without making any attempt to push the former; in others she pushed, but did not wait for the catch to spring. 
During the first days of the retention tests she frequently leaped into the air, whirled through 180 degrees, and snapped her jaws repeatedly, or at other times spun about in a similar manner and bit her own tail. Another movement which occurred frequently was a sort of scampering, a series of short leaps which did not carry her forward more than a few inches. These movements, as well as the inexactness of the reactions to the plane served to prolong the time and make it less comparable with the time of learning. Training was continued for 45 trials after the operation. The average time for the first five trials of the retention tests was: to plane, 63 seconds; to door, 23 seconds. The rate of improvement was more uniform and at first more rapid than that observed during learning, but the time required for springing the catch was not reduced so low as it had been before the operation. The rate of learning and of improvement in the retention tests are shown in figure 8 , where the total time required for successive groups of five trials is plotted.

Lesions (plate III, fig. 20). Right hemisphere. There is a transverse lesion on the anterior covexity, passing forward along the fibers of the callosum and through the end of the forceps of the callosum to the base of the olfactory bulb, completely separating the frontal pole.

Left hemisphere. The lesion is quite similar to that on the right but does not extend quite to the olfactory bulb and preserves the greater part of the mesial face of the frontal pole.

After nearly complete destruction of the frontal poles of both hemispheres this rat retained her previous method of tripping the catch. There was, however, some inaccuracy of movement indicating a partial loss of the habit.

Experiment 21. The frontal pole of the cortex was destroyed in a small female, 130 days old. She had been trained for 40 trials on the inclined-plane box. The average time required for the first five trials was: to plane, 618 seconds; to door, 74 seconds. The average time required for the last five trials was: to plane, 5.2 seconds; to door, 1.8 seconds.

Retention was first tested on the day following the operation. 
The animal was stuporous and did not react to the problem situation. On the following day she was active and gave evidence of hunger. She was given five trials on this day and five trials per day thereafter for 8 days. The average time per trial for the first five trials of the retention tests was: to plane, 81 seconds; to door, 42 seconds. In the tests on the first day she used no uniform method of springing the plane; she once pulled

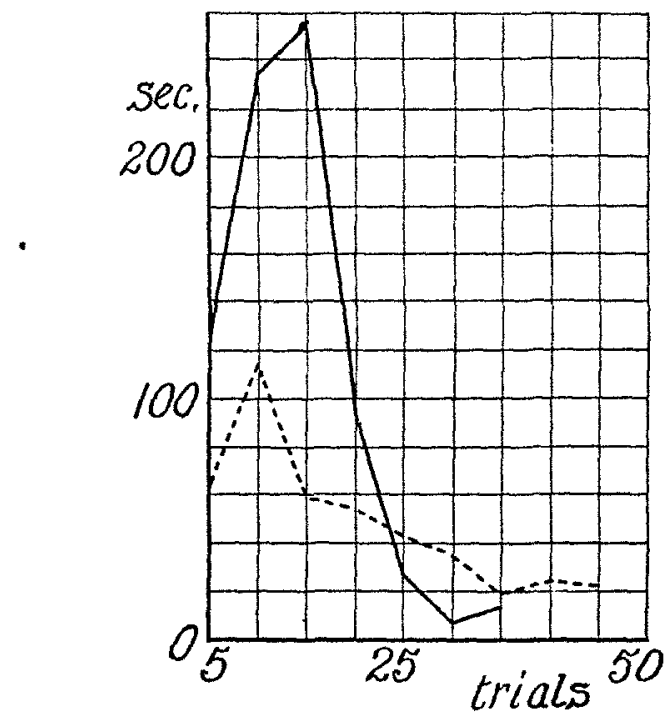

Fig. 8. Rate of Improvement in Training and Retention Tests. The Average Time per Successive Five Trials is plotted FOR EXPERIMENT 20

Learning -

it up from behind, once jumped up on it from in front of the food box, once walked straight across it from the back of the box, and twice walked out on it from the rear. After the fourth trial she adopted this latter method and used it uniformly in succeeding trials, varying the method only rarely by pushing down the plane with her fore feet. In the learning trials she had uniformly climbed up from the rear of the box and tripped the catch by pushing the plane down with her fore feet. 
The curves of the learning and retention tests are given in figure 9 . It is evident that very much less time was required for the solution of the problem at the beginning of the retention tests than at the beginning of learning, but that improvement was relatively slower. Apparently the plane retained a certain stimulatory value, much like that which it acquires in the early stages of learning, but did not at first call out the appropriate reactions for getting food.

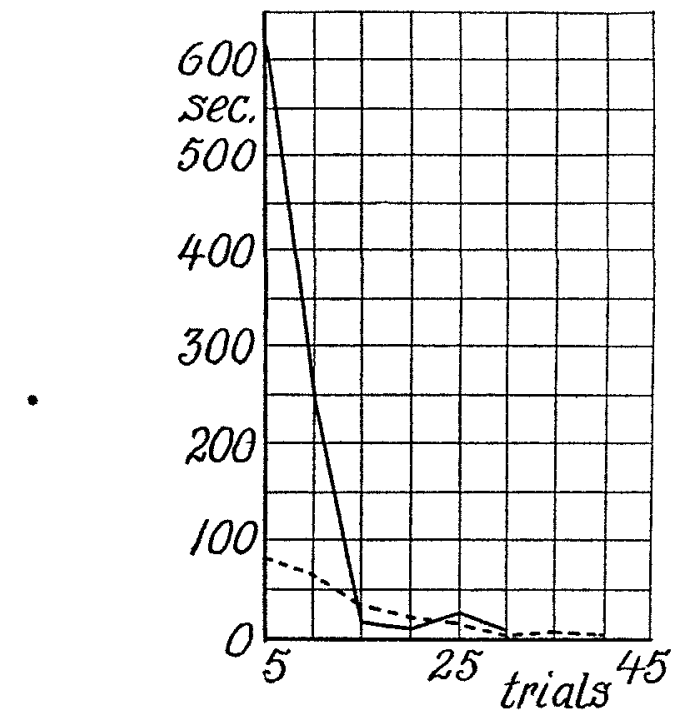

Fig. 9. Rate of Improvement in Training and Retention Tests for EXPERIMENT 21

Arranged as figure 8

Lesions (plate III, fig. 21). Right hemisphere. There is a transverse lesion extending from just behind the knee of the corpus callosum laterad to the cortex and diagonally ventrad through the base of the olfactory bulb. The greater part of the mesial face of the frontal pole is intact but there is a probable destruction of all the antero-lateral area.

Left hemisphere. There is a transverse lesion extending from the anterior horn of the lateral ventricle along the forceps of 
the corpus callosum to the external capsule and downward to the floor of the ventricle. It probably involves very little destruction. There is also a lesion extending into the mesial cortex just back of the knee of the corpus callosum, destroying a small area. There is a partly absorbed clot in the third ventricle.

In this animal three-fourths of the cortex on one frontal pole and about one-eighth on the other were destroyed. The habit was partly retained. The reactions after the operation resembled those appearing in the early stages of learning before a stereotyped mode of solving the problem has been acquired.

Experiment 22. Transverse incisions were made in the frontal areas of the cortex of a large male, 140 days old, through two trephine holes in the temporal regions. The animal had been trained for 40 trials on the inclined plane box. The average time per trial required for the first five trials of training was: to plane, 330 seconds; to door, 38 seconds. The average time per trial for the last five trials was: to plane, 6.6 seconds; to door, 3.2 seconds.

Retention was tested on the day following the operation but the animal was stuporous and did not attempt to climb upon the food box. On the third day he climbed upon the box but got down immediately and remained quiet in a corner for 20 minutes. On the fourth day after the operation he climbed on the box and fell off, striking the back of his head and lying stunned for 30 seconds. When he recovered he climbed up on the box, walked out on the plane from the rear and then went directly to the food. The remaining trials were made quickly. The average time for the first five trials, exclusive of the one in which the fall occurred was: to plane, 45 seconds; to door, 5.6 seconds. The tests were continued for 30 trials, which are compared with the first practice series in figure 10 . In the first tests he made frequent trips from the plane to the door and made few pauses at other parts of the restraining cage. In later practice he acquired the habit of jumping up from the door to the back of the plane, then walking out to the free end of the plane. This was not the most frequent method that he had employed during learning. 
Like the animal in experiment 21 he seemed to retain a general response to the region of the plane but to have lost the specific reactions used in springing it.

Lesion (plate III, fig. 22). Right hemisphere. There is a vertical transverse lesion extending downward from the anterior horn of the lateral ventricle to the cerebral peduncle, without

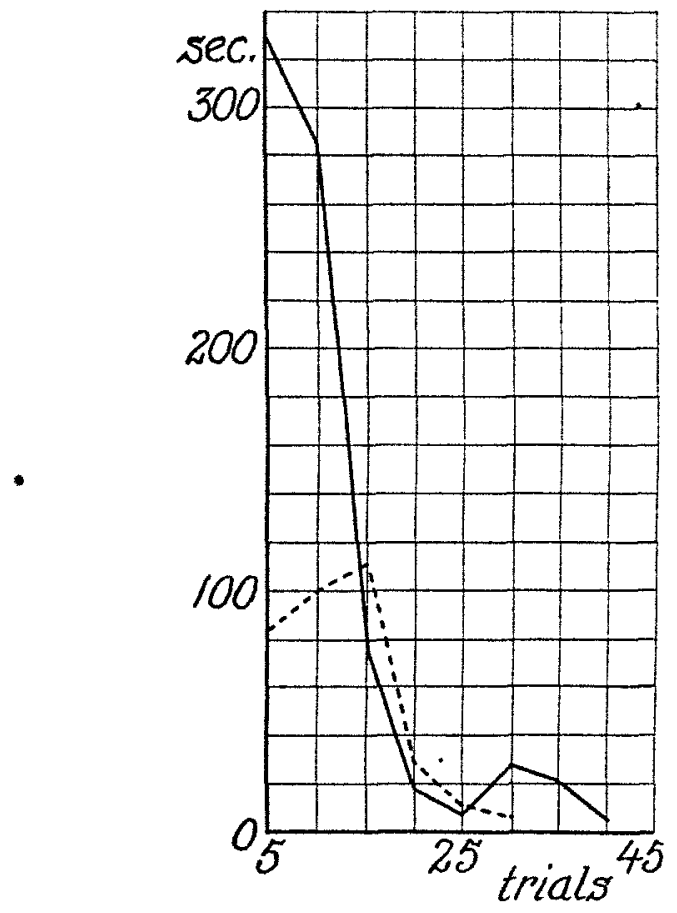

Fig. 10. Rate of Improvement in Training and Retentron Tests for Experiment 22

Arranged as figure 8

involving this, however. On the antero-dorsal convexity there is a lesion corresponding to the trephine opening, with the cortex cephalad to it somewhat degenerated. The deeper lesion involves little destruction, as the cut follows the course of the fibers.

Left hemisphere. The lesion on the dorsal convexity is somewhat larger than that on the right. There is a large cavity 
in the region of the external capsule opposite the corpus striatum with degeneration of the fibers and cortex laterad to it, and invasion of the cerebral peduncle in the region receiving fibers from the mesial surface of the frontal pole.

Bilateral destruction of the cortex above the knee of the corpus callosum with degeneration on the orbital and mesial surfaces of the left hemisphere was followed by a partial loss of the habit including the definite mode of depressing the plane.

Experiment 23. The frontal areas of the cortex were transected through two trephine holes in a small male rat, 149 days old. He had been trained previously on the inclined-plane box for 100 trials. The average time for the first five trials of practice was: to plane, 332 seconds; to door, 48 seconds. The average time for the last five trials was: to plane, 10.2 seconds; to door, 2.2 seconds. During the training he developed an absolutely stereotyped method of tripping the plane. He ran first to the door, jumped up from there upon the food box in such a way as to alight upon the free end of the plane, turned and jumped down to the floor in front of the door and went in to the food.

Retention was first tested on the second day after the operation. The animal was fairly active, sniffed at the door of the food box and stood up and sniffed the plane repeatedly but made no effort to get upon the box in thirty minutes. On the fifth day after the operation he first showed marked activity comparable to that of a normal animal. For the first four trials he climbed to the top of the box always from the door, but gave no specific reaction to the plane, in each case pushing it down apparently by chance and using a different method each time. On the fifth trial he went first to the door, jumped up upon the lower end of the plane, then turned quickly and jumped down to the door. This was repeated five times before he alighted on the outer end of the plane. During the next ten trials he invariably jumped up from the front of the box to the plane, and then down to the door again, repeating this performance as often as fifteen times in a single trial before he alighted on the free end of the plane. This was due in part to 
the fact that he was too weak to jump the full distance readily and usually jumped from near the side of the restraining cage, catching its wires if he fell short. In the repeated failures to open the door by jumping up at this place a new method of working the plane was gradually evolved; he came to scramble up over the lower end of the plane, turn and push down on its free end until the door opened.

The average time per trial for the first five trials of the retention tests was: to plane, 176 seconds; to door, 13 seconds. The relations of the practice curves of learning and retention are practically the same as for those shown in experiments 20 , 21 , and 22 .

Lesion (plate III, fig. 23). Right hemisphere. There is a transverse incision extending cephalad from above the hippocampus through the lateral ventricle and caudal end of the corpus striatum to the peduncle. The internal capsule and the fibers of the peduncle are uninjured, so that the lesion probably involves little more than the superficial areas through which the knife passed. This includes the greater part of the cortex above the corpus callosum and a narrower band extending down over the orbital surface.

Left hemisphere. There is a transverse lesion extending from above the anterior border of the hippocampus to the base of the olfactory lobe, transecting the corpus striatum and completely severing the portion of the cortex lying cephalad to it.

Destruction of all of the left frontal region and the temporal region of the right was followed by the retention of the stereotyped mode of reacting to the problem box but with inaccuracies of adjustment which resulted in the acquirement of a new mode of response.

Experiment 24. The frontal poles of both hemispheres of a medium sized female rat, 147 days old, were incised through large trephine holes, well back of the fronto-parietal suture. She had been trained previously for 75 trials on the inclinedplane box. The average time per trial required for the first five trials of training was: to plane, 2422 seconds; to door, 23 
seconds. The average time for the last five trials was: to plane, 15.4 seconds; to door, 2.4 seconds. Retention was tested on the second day after the operation. She reacted promptly to the problem-box situation, never pausing except at the door and at the plane. She tripped the plane by one of two methods; either she jumped up from in front of the door so that her hind feet struck the free end of the plane, or, this method failing, she turned and pushed the plane down with her fore feet. These were the methods used before the operation. The average time required for the first five trials of the retention tests was: to plane, 37.6 seconds; to door, 9.6 seconds.

Lesion (plate III, fig. 24). Right hemisphere. There is a small lesion on the antero-dorsal convexity corresponding to the extent of the opening of the skull. From this a transverse cut extends ventrad through the union of the forceps of the corpus callosum with the external capsule to the base of the olfactory bulb. Its effects are limited to the lateral face of the cortex where there is a narrow degenerated area along the edges of the cut, widening on the orbital surface.

Left hemisphere. The lesion is almost identical with that on the right but less extensive on the orbital surface.

Destruction of the antero-lateral faces of the cortex in this animal resulted in practically no loss of the habit.

Frontal region destroyed: animals showing questionable retention after operation

Experiment 25. The frontal poles of the cerebrum of a small male rat, 143 days old, were destroyed by incisions through two large openings in the parietal bones, $5 \mathrm{~mm}$. back of the frontoparietal suture. The animal had previously been given 45 trials in the inclined-plane box. The average time required for the first five trials was: to plane, 575 seconds; to door, 40 secopds. The average time for the last five trials of training was: to plane, 9.6 seconds; to door, 2.8 seconds.

Retention was first tested on the fourth day after the operation as the animal was quite stuporous up to this time and had to be fed by hand. On this and the following day he moved 
slowly about the floor of the restraining cage but made no attempt to climb up to the plane in more than an hour. On the following day he was more active but gave marked fear reactions, squeaking and jumping blindly against the sides of the cage when touched and biting at the experimenter's hands or at his own feet when he was picked up. This behavior persisted for four days, then he became more normal and on the eighth day after the operation he solved the problem box five times. On the following day he was spastic and on the tenth day after the operation died. His average time per trial on the five successful trials was: to plane, 138 seconds; to door, 50 seconds. At no time in the retention tests did the plane seem to have any more intense stimulating value than other parts of the problem situation. The only evidence for retention is the short time required for solving the problem, and this may be merely a chance variation.

Lesion (plate III, fig. 25). Right hemisphere. There is a lesion over the dorsal surface of the gyrus hippocampus, extending cephalad along the roof of the lateral ventricle, then ventrad through the knee of the corpus callosum, transsecting the corpus striatum and extending to the base of the hemisphere. A large cyst has been formed filling the greater part of the frontal pole and the anterior half of the corpus striatum is degenerated.

Left hemisphere. There is a large pit on the dorsal convexity, extending down around the gyrus hippocampus and a transverse incision extending from this through the anterior horn of the lateral ventricle to the base of the olfactory bulb, completely severing the anterior pole.

After practically complete destruction of the anterior third of both hemispheres this animal succeeded in solving the inclinedplane problem in considerably less time than that usually required by normal individuals and in less than one fourth of the time which he took for an equal number of trials in the initial training.

Experiment 26. The frontal poles of both hemispheres of a small male rat, 143 days old, were incised through large openings in the parietal bones. He had been trained on the inclinedplane box for 40 trials. The average time required per trial 
for the first five trials was: to plane, 721 seconds; to door, 35 seconds. The average time per trial for the last five trials was: to plane, 5.4 seconds; to door, 2.4 seconds.

Retention was tested first four days after the operation. The animal was still stuporous and on this and the following day made no attempt to get upon the food box. On the seventh day after the operation he ran actively back and forth from the door to the back of the food box and tripped the plane twice by climbing up over it from the door. On the following day he was stuporous but on the ninth day he solved the problem five times quite rapidly. Thereafter he became progressively worse and died on the fourteenth day after the operation.

The average time per trial for the first five trials of the retention tests was: to plane, 179 seconds; to door, 26 seconds. This is less than one fourth of the time required for the first five trials of training and indicates some degree of retention although no specific habits of reaction to the plane which had been noted before the operation were observed to persist.

Lesion (plate III, fig. 26). Right hemisphere. There is a transverse lesion extending diagonally forward and downward from just above the hippocampus through the lateral ventricle to the base of the olfactory bulb. The corpus striatum is cut in two transversely. The entire frontal pole is probably nonfunctional.

Left hemisphere. The lesion is very similar in form to that on the right but penetrates less deeply toward the mesial surface and probably leaves the mesial cortex functional.

After extensive destruction of the antero-lateral regions of both hemispheres this animal gave no indication of the retention of specific habits of reaction to the plane. However, even though he was stuporous for much of the time, he required only one fourth as much time for the retention tests as for corresponding tests in initial learning. 
Frontal pole destroyed: animals in which the habit was lost but reacquired after operation

Experiment 27. The frontal poles of the cortex were incised in a small female rat, 145 days old, through two trephine holes at the frontal-parietal suture. The animal had been given 30 trials on the inclined-plane box. The average time required for the first five trials was: to plane, 396 seconds; to door, 23 seconds. The average time per trial for the last five trials was: to plane, 24 seconds; to door, 4.0 seconds. The animal was very weak from the operation and could not be tested for eight days. On the ninth and tenth days she was very spastic and remained motionless in the restraining cage. On the eleventh day she first tripped the catch and on the following days improved considerably in the directness of her approach to the plane but never reached her previous efficiency. Throughout the period of retraining she remained spastic and lost weight rapidly. During the first trials of retraining there was never any indication of the retention of any specific mode of reacting to the problem box. The average time per trial for the first five trials of the retention tests was: to plane, 599 seconds; to door, 65 seconds.

Lesion (plate III, fig. 27). Right hemisphere. There is a transverse section passing over the anterior face of the gyrus hippocampus, through the lateral ventricle to the base of the hemisphere, separating all parts of the cortex in front of the anterior horn of the lateral ventricle. The corpus striatum is completely destroyed and the lesion extends caudad from it along the external capsule to the hippocampus, with degeneration of all the cortex laterad to it.

Left hemisphere. The lesion is less extensive, passing ventrad just behind the knee of the corpus callosum to the base of the olfactory bulb and out diagonally through the anterior end of the corpus striatum to the cortex, severing the anterior pole.

The destruction of the anterior poles of both hemispheres, of part of the orbital surface of one hemisphere, and of all of one and part of the other corpus striatum was followed by a persistent spas- 
ticity and by a complete loss of the motor habit. The habit was reacquired with normal rapidity at first but a normal degree of proficiency was not attained.

Experiment 28. The frontal poles of the cortex were destroyed in a large male, 140 days old. He had been trained on the inclined-plane box for 30 trials. The average time per trial was for the first five trials: to plane, 2594 seconds; to door 224 . That for the last five trials was: to plane, 22.0 seconds; to door, 1.6 seconds.

Retention was tested on the day following the operation but no approach to normal activity was obtained until the third day. He then tripped the plane three times, requiring an average time of: to plane, 493 seconds; to door, 79 seconds. For the following week he did not get upon the food box in a total of six hours spent in the restraining cage. He then became active again and eventually learned the problem, requiring àbout the same time as in the initial practice to reduce his average time to less than 30 seconds. In the early trials of the retention tests there was no uniformity in the method of tripping the plane and there was never any indication of the retention of a specific habit of reaction.

Lesion (plate III, fig. 28). Right hemisphere. There is a lesion of the dorsal convexity over the gyrus hippocampus and extending forward around the anterior surface of the hippocampus, along the roof of the lateral ventricle and ventrad in front of the knee of the corpus callosum through the peduncle, severing the frontal pole. The entire lobe in front of the corpus striatum is degenerated and filled by a large cyst.

Left hemisphere. The lesion is similar to that on the right, but extends farther back along the external capsule, with degeneration of a part of the orbital cortex. Only the outer half of the peduncle is injured so that the mesial surface of the lobe is probably functional.

After almost total destruction of both anterior poles of the cortex in front of the corpora striata this animal completely lost the habit of the inclined-plane box, but acquired it again in about the same time as was required for initial learning. 
Frontal pole destroyed: animals which lost the habit after operation and failed to acquire it again

Experiment 29. The frontal poles of both hemispheres were incised in a large male rat, 155 days old. He had been trained for 85 trials on the inclined-plane box. The average time per trial for the first five trials was: to plane, 2311 seconds; to door, 51 seconds. That for the last five trials was: to plane, 8.9 seconds; to door, 2.8 seconds.

The animal was tested daily for a week after the operation but did not once get on top of the food box. His activity was equal to that of a normal animal but was confined to a few stereotyped movements. He spent a great deal of time in climbing up the sides of the restraining cage and pushing against the wire top with his nose. This was gradually replaced by a rapid pacing around the food box from the door to the back and to the door again, interspersed with long pauses in front of the door of the food box, which continued day after day without variation. There was no indication of the retention of any part of the habit.

Lesion (plate III, fig. 29). Right hemisphere. There is a lesion through the lateral ventricle, passing laterad through the posterior third of the corpus striatum to the cortex and ventrad through the peduncle. There is a second lesion over the frontal pole with complete degeneration of the cortex and formation of a cyst. It is probable that the section of the cerebral peduncle destroyed the lower connections of all the frontal region.

Left hemisphere. There is an extensive superficial lesion over the convexity of the frontal pole with a transverse cut extending laterad from the lateral ventricle to the cortex in front of the corpus striatum, following the course of the fibers and probably doing very little damage.

After a complete section of one cerebral peduncle, destruction of the frontal pole on that side, and destruction of half the cortex of the frontal region on the other side this animal gave no evidence of retention of the habit, and failed to reacquire it within the limits of the experiment. 
Experiment 30. The frontal poles of the cortex of a meditum sized male rat, 140 days old, were transsected with a spearpointed needle, introduced through small trephine holes in the parietal bones just behind the fronto-parietal suture. The animal had been trained for 25 trials on the inclined-plane box. The average time per trial for the first five trials was: to plane, 3382 seconds; to door, 39 seconds. That for the last five trials was: to plane, 43.0 seconds; to door, 10.4 seconds. During training the animal developed an easily recognizable method of springing the plane. He regularly placed his right fore foot on the end of the plane and kept it there while he thrust his nose under the plane. In this position his weight was supported largely by the right fore foot and the end of the plane was pulled down.

Retention was tested first on the second day after the operam tion while the animal was still weak and stuporous. He moved about slowly, smelling in the corners of the restraining cage and once crossed the top of the food box but gave no specific reaction to the plane. He was tested daily for thirty minutes thereafter for fourteen days. For the first three days he was very active and quite wild, squeaking and jumping whenever touched; later he became tame but rarely moved away from the door of the restraining cage.

Lesion (plate III, fig. 30). Right hemisphere. There is a lesion of the cortex above the dorsal and lateral surfaces of the gyrus hippocampus with prolongation of the lateral ventricle along the external capsule into the occipital lobe with probable degeneration of all the fibers in this region. There is a complete separation of the hippocampus from the external capsule with probable degeneration of the fibers in the capsule. There is a transverse lesion also extending forward along the corpus callosum, around the knee to the floor of the lateral ventricle, and laterad through the anterior end of the corpus striatum to the external capsule. This lesion does not penetrate far enough to injure the peduncle so that the ventro-lateral face of the frontal pole is probably intact.

Left hemisphere. There is a transverse lesion extending 
from above the gyrus hippocampus, through the anterior end of the fornix and the corpus striatum to the base of the olfactory bulb, completely severing the anterior pole.

Both corpora striata were injured but show no sign of degeneration except along the edges of the cut.

With almost complete destruction of the frontal poles of both hemispheres and a probable degeneration of much of the cortex on the orbital and occipital regions of the right hemisphere this animal showed a complete loss of the habit and a failure to relearn the problem.

Experiment 31. The frontal poles of both hemispheres were incised in a small female rat, 148 days old. She had been given 100 trials on the inclined-plane box, requiring as an average time per trial for the first five trials: to plane, 591 seconds; to door, 67 seconds. For the last five trials these averages were: to plane, 5.4 seconds; to door, 3.2 seconds.

Retention was tested on the second day after the operation. The aninal was very weak, but ran about actively in the restraining cage and twice crossed the plane without giving any specific reaction to it. On the following day she spent thirty minutes climbing up to the top of the restraining cage and falling back to the floor. She ran across the top of the food box several times and in each case pitched off on her head without making any attempts to catch the side of the box. For the next two days her activity in the restraining cage was greater than that of a normal rat, but was restricted wholly to attempts to climb around the sides of the restraining cage just below the top, with repeated heavy falls. On the sixth day after the operation she died.

Lesion. The brain of this animal was lost.

Experiment 32. The frontal pole of the cerebrum was transected through two large trephine holes in the parietal region of a small female rat, 146 days old. She had been trained on the inclined-plane box for 55 trials. The average time per trial for the first five trials was: to plane, 945 seconds; to door, 145 seconds. That for the last five trials was: to plane, 7.2 seconds; to door, 2.6 seconds. 
Retention was first tested on the second day after the operation. The animal moved about the floor of the restraining cage for a few minutes, then settled down and remained motionless. The same thing happened on the next three days. On the sixth day she became very spastic and during the tests passed through a series of prolonged tonic spasms, exhibited in arching of the back, retraction of the head, and gradual extension of the legs and feet so that she came to stand only on the tips of her toes. This appeared after every rapid movement and persisted for sometimes as much as two minutes. On the following day she was still more spastic and the spasms intervened at every attempt to walk. On the ninth day after the operation she had partly recovered and succeeded in tripping the plane four times. The average time for these four trials was: to plane, 1117 seconds; to door, 70 seconds. On the following days she again became spastic and showed no further improvement in two weeks.

Lesion'(plate III, fig. 32). There is a transverse lesion completely separating the frontal poles of both hemispheres from the remaining cortex, along a plane extending from the anterodorsal face of the hippocampus, through the forceps of the corpus callosum to the base of the olfactory bulbs. There is a separation of the left corpus striatum from the external capsule and a partial invasion of the nucleus by large blood vessels. There is a similar degeneration of the anterior end of the right corpus striatum.

After complete destruction of the frontal poles of both hemispheres and partial destruction of the cerebral nuclei this animal gave no evidence of retention of the habit.

Experiment 39. Operation on the frontal poles of the cerebrum in a large female rat, 142 days old. She had been trained for 120 trials on the inclined-plane box. The average time per trial for the first five trials was: to plane, 2970 seconds; to door, 28 seconds. That for the last five trials was: to plane, 34 seconds; to door, 2.2 seconds.

Retention was tested on the second day after the operation. The animal was seemingly in good condition, ran about actively 
and seemed fairly normal in behavior. She was placed in the restraining cage and ran about actively for five minutes but did not get up to plane. She seemed suspicious and explored with neck extended. She then settled down at the back of the box and remained motionless for an hour. On the two days following this behavior was repeated. There was never any specific reaction to the situation and after the first five minutes there was no normal exploration; she did not get on top of the food box in three hours on three consecutive days. She also was abnormally wild and tried to escape when picked up.

Lesion (plate III, fig. 33). Right hemisphere. There is a lesion extending diagonally forward from above the hippocampus along the course of the external capsule over the corpus striatum to the base of the olfactory bulb, severing all the fibers laterad to the forceps of the corpus callosum but leaving the mesial surface of the pole intact. The lesion is filled by a large clot.

Left hemisphere. The lesion extends somewhat farther back than that on the right, passing down through the anterior third of the corpus striatum into the lateral half of the cerebral peduncle. The mesial surface of both hemispheres is probably intact.

After destruction of the antero-lateral pole of both hemispheres this animal gave no evidence of retention.

Seventeen animals are reported in this series. The extent of injury and the degree of retention is given in the following table.

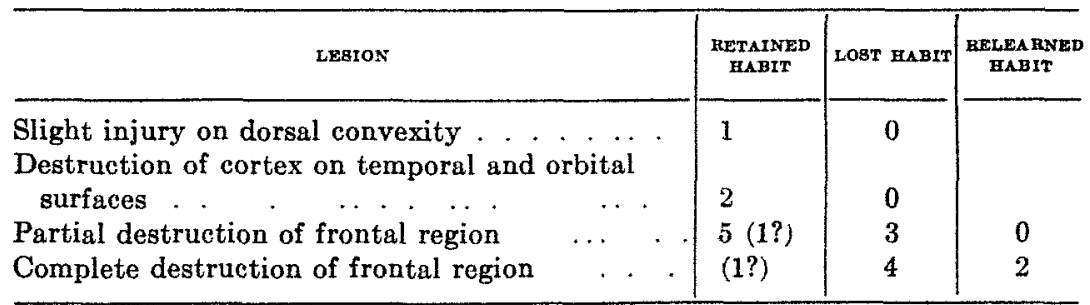

After partial or complete destruction of the frontal poles of both hemispheres some of the animals retained the habit, others lost it, and of these some reacquired it after training and others 
failed. What is the relation of these differences of behavior to the extent of the cerebral destructions? The figures of the brains are grouped on plate III for comparison. The first fact evident from the figures is that in every case where there was a clear retention of the habit the destruction of the anterior pole of one or both hemispheres was incomplete. In animals which showed a loss of the habit there is apparently a greater destruction of cortex, so that in most if not all cases the whole of both frontal poles is involved.

It is impossible to say how sharp is the distinction between these two groups when the extents of the lesions are compared. The maximum extent of the lesion has not been determined accurately in any case and the figures are based almost wholly upon the gross lesions. It is probable, however, that these are at least indices of the true extent of injury.

Among the animals which showed no retention there was a practically complete destruction of the frontal poles of both hemispheres in experiments 27,30 and 32 , with almost complete destruction in experiment 28 . In two of the remaining a part of the mesial cortex was preserved; the extent of the lesion was not determined in the third. One animal which showed doubtful retention (experiment 25) was also found to have a complete destruction of the frontal region of both hemispheres. The only evidence for retention in this case was the solution of the problem in less than the normal learning time. There was no recognizable reaction to the plane which persisted after the operation and the successful movements were made as though by chance. The long average time ( 50 seconds) required by the animal to reach the food after tripping the plane gives further evidence that there was little or no retention of the habit. Allowing for the questionable nature of the retention in this last animal, we are justified in concluding that the complete destruction of the frontal region of the rat's brain results in the loss of the complex inclined-plane habit.

After partial destruction of the frontal pole five animals retained the habit, one gave questionable evidence of retention and two showed no retention of the habit. Of the latter, one 
(experiment 29) developed an abnormal stereotyped reaction to the situation and the other (experiment 33) was stuporous during most of the tests so that the two animals scarcely provide data from which reliable conclusions can be drawn. With the exception of these two and the questionable case described in experiment 26, the animals with partial injuries to the frontal pole gave clear evidence of retention of the habit. Among them the one described in experiment 20 showed the most extensive lesion, only the left mesial region being left intact (plate III, fig. 20). In the others the lesions were more restricted, leaving the frontal pole of one or other hemisphere intact. This sug-

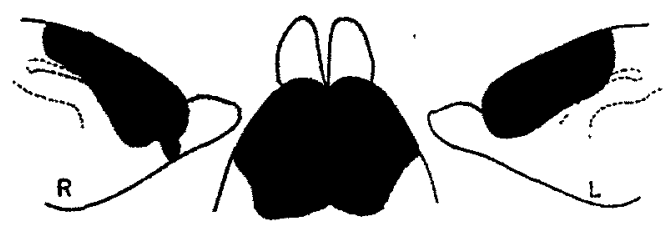

Fyg. 11. Total Extent of Legion in Animals of Series IV Which Retained THE HABIT

gests the question whether or not there is some particular part of the frontal region concerned with the retention of the habit. Figure 11 shows the combined extent of the lesions in the animals retaining the habit. Every part of the frontal region was destroyed in one or another of the operations.

It seems, then, that although some part of the frontal region must remain intact if the plane-box habit acquired by the normal animals is to be retained, the particular part preserved is immaterial. The different parts of the frontal region are, to adopt a term from experimental embryology, equipotential in the functioning of the habit.

v. HABIT FORMATION AFTER DESTRUCTION OF LARGE AREAS OF THE CORTEX

In spite of many dogmatic assertions concerning the function of the cerebrum in so-called associative memory we have not a single published account of any experiments which give con- 
clusive evidence that the cerebrum is or is not necessary for habit formation. Burnett (4) failed to get decerebrate frogs to learn a simple maze but it is possible either that the operation resulted in such a disintegration of the animal's other habitual reactions that the incentive for learning the maze was no longer adequate, or that the maze presented a too complex habit and that a simpler habit might still have been acquired. The experiments certainly do not justify the author's sweeping conclusion that learning is not possible in the absence of the cerebral cortex. The statement in the introduction that learning is possible in the decerebrate frog is based upon unpublished results on the facilitation of the crossed reflex of the hind leg. ${ }^{1}$ Goltz (5) made an attempt to train his decerebrate dog but gave up quickly for fear that the training methods would result in the animal's death. Rothman (6) reported the acquirement of new motor coördinations in his decerebrate dog but gave no details of the experiment. It is not possible to be certain that the changes in behavior noted by these authors were not concomitants of recovery from operative shock rather than true examples of habit formation.

It may be that no complex habits are acquired in the absence of the cerebral cortex but a fundamental point in the problem of the physiology of learning is involved in the possibility of the formation of simple habits wholly by the mechanisms of the spinal cord and brain stem. Is there any fundamental difference between the organization of the cerebrum and that of lower centers such as to give the former special functions which are lacking to the more primitive portions of the nervous system, or are the cerebral and spinal functions alike save for the possibility of greater complexities of reflex connections within the cortex? Failure or success in obtaining habit formation in

\footnotetext{
1 Some may object to this as an example of learning, but it is undoubtedly true that any modification of an animal's behavior due to repeated stimulation (exclusive of fatigue phenomena) is properly called learning. The distinction between "associative memory" and other types of acquired reactions is by no means so clear as the exponents of this as a criterion of consciousness would have us believe.
} 
decerebrate animals will furnish significant evidence for this problem.

As yet we have not been able to effect a complete decerebration of the rat but by the destruction of large and varied areas we have obtained evidence, perhaps not yet conclusive, that the cerebral cortex is not functional in the formation of simple habits.

A number of animals were operated upon to destroy the cortex over the dorsal, temporal, and frontal regions and such parts of the orbital and occipital surfaces as could be reached from above without lesion to the thalamus. Six of these survived and all have been trained successfully in the formation of simple habits. A record of the experiments is given below.

In the diagrams of the brains of this series of animals (plate II, figs 34 to 39) the solid black areas represent the parts from which the cortex has been completely absorbed, the stippled areas those in which there was degeneration or evident loss of function through destruction of fibers.

Experiment 34. A large opening was made in the calvarium of a large adult male rat and a scalpel (curved on the flat) was drawn around the frontal and temporal lobes on each side and thrust backward to the tentorium. On the day following the operation the animal began to walk about. He was very spastic, with back arched constantly, and occasionally remained motionless for long periods in contorted positions. 'He would not eat, but drank milk when it was placed in his mouth and when his short vibrissae were touched with a pipette filled with milk he grasped the end of it with his teeth. He would not do this in response to a stick unless it were wet with milk. This reaction suggests the retention of smell. He gave no detectable reactions to light, to light contact, or to aromatic odors which are avoided by normal rats. He reacted to loud sounds, to heavy contact or diffuse pressure, and to protopathic stimuli.

On the second day he ate when his lips were pressed against the food, but when his movements carried him away from the food he continued to gnaw at the edge of the food dish for some time. During the ten days that he was kept alive he never 
learned to find food by himself and had to be fed, chiefly with milk given from a pipette.

Training. He was fed five or six times a day by placing the end of a pipette between his teeth and squirting milk into his mouth. He almost immediately began to reach for the pipette as soon as it was brought in contact with his short vibrissae. An attempt was made to train him to inhibit this reaction. He was first given a taste of milk, the pipette was then wiped off and brought in contact with his short vibrissae. He took hold of it but, getting no milk, let go immediately. This was repeated every five seconds for fifty-five times with the following results. He reacted every time in the first five trials, four

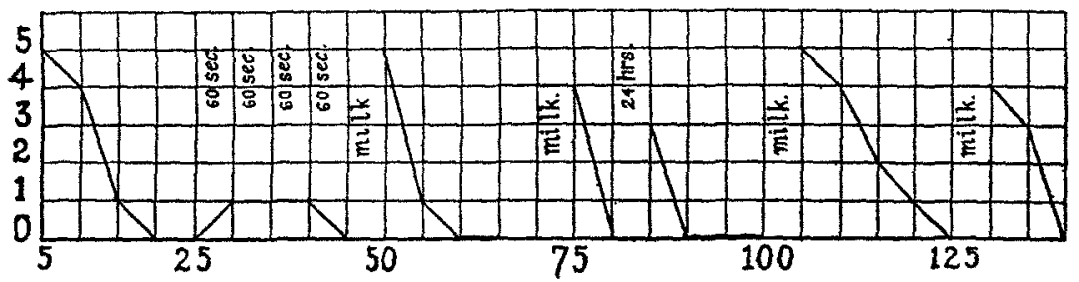

Fig. 12. Rate of Learining to Reject Empty Pipetre

The number of times that the pipette was taken in successive groups of five trials is plotted.

times in the second five, once in the third, and not once in the fourth and fifth. After a 60 second interval ten more trials were made. He reached for the pipette the first time but not again. After another 60 second interval he reached once again, then failed to reach for nine trials; so after a third interval. After the fourth interval of 60 seconds he did not reach once in ten trials. Milk was then placed in his mouth twice, the pipette was wiped and offered again. It was grasped five times in the first five trials, once in the second five, and not thereafter. Milk was given again and after this he reached for the pipette four times in the first five trials, four times in the second, and not in the third and fourth. Quite similar results were obtained on the following day. The complete series is given in figure 12 . 
On the following days he became more and more deteriorated and was finally killed as he could no longer be induced to eat.

An attempt was made to establish a conditioned reflex to contact with the foot. The animal was fastened in the container designed by Watson and the foot was fastened to a pointer in contact with a kymograph. The dorsal surface of the foot was then stimulated first by rubbing with the uncharged electrodes, then electrically. The first effect of electric stimulation is a quick jerk of the foot followed by an increased tonic contraction of the muscles for standing so that the animal, with repeated stimulation, rises gradually until he stands on the tips of his toes and maintains that position for as long as three minutes.

In the apparatus the animal's reactions became more and more violent until, after the fourteenth stimulation he began to bite his thigh and had to be taken out. For five minutes thereafter, when his right hind foot was touched he reacted by turning his head to the foot and squeaking. Fifteen minutes later no reaction to contact with the foot was given.

Lesion (plate II, fig. 34). The brain of this animal was one of those improperly sectioned so that an exact delimitation of the destroyed area has not been possible. As nearly as can be determined there is a total destruction or degeneration of all the cortex lying above and laterad to the third and lateral ventricles, a separation of the frontal pole from all underlying structures at the level of the cerebral peduncles, a great shrinkage of both corpora striata, and a destruction of the medial portion of the occipital lobes.

This animal had probably the greatest destruction of cerebral tissue of any reported in this study. His instinctive exploratory reactions were so limited that training on the ordinary laboratory problems was impossible. He nevertheless showed an ability to form very simple habits quite rapidly.

Experiment 35. Deep transverse and horizontal incisions were made in the cortex of a large male rat, 115 days old. $\mathrm{He}$ recovered rapidly from the operation and gave no evidence of motor disturbances or of other abnormality of behavior.

Training in the simple maze (fig. 1) was begun six days after 
the operation. He required only thirty trials to learn to go to the right. He was then required to go to the left and the earlier habit was completely overcome in twenty trials. The records of time and errors are given in table 1.

TABLE I

Rate of learning for rat described in experiment $\$ 5$. In this and the following tables the average time per trial and the total number of errors are given for successive groups of five trials

\begin{tabular}{c|c|c|c}
\hline \multicolumn{2}{c|}{ To Rratr } & \multicolumn{2}{|c}{ To LEF } \\
\hline Time & Errors & Time & Errors \\
\hline 430 & 3 & 28.0 & 4 \\
35.5 & 3 & 8.0 & 1 \\
16.5 & 1 & 7.5 & 0 \\
8.5 & 0 & 65 & 0 \\
7.5 & 0 & & \\
65 & 0 & & \\
\hline
\end{tabular}

$\mathrm{He}$ was killed 30 days after the operation. Microscopic examination of the brain showed (plate II, fig. 35):

Right hemisphere. A transverse lesion beginning above the posterior end of the corpus callosum and extending forward almost horizontally to the anterior pole, above the level of the corpus callosum. There is a superficial lesion of the lateral surface of the occipital lobe resulting from a knife cut which separated the cortex from the underlying fibers. A similar lesion extends over the orbital surface, separating nearly half of the lateral surface of the cortex from the underlying fibers and destroying the fibers of the external capsule back to the level of the hippocampus. The lateral ventricle was not reached by the injuries and the subcortical ganglia are intact.

Left hemisphere. The lesion on the dorsal convexity is similar to that on the right. There is a transverse lesion completely severing the frontal pole just in front of the caudate nucleus. A lesion on the orbital surface following the course of the external capsule to the anterior end of the hippocampus has completely destroyed a lens-shaped area on the orbital surface. The cerebral nuclei are intact. 
After the destruction of somewhat more than the anterodorsal third of the cortex, together with a large area on the right occipital lobe, this animal showed no detectabse abnormality in behavior or in the rate of habit formation.

Experiment 36 . A transverse opening 10 by $8 \mathrm{~mm}$. was made in the calvarium of a small female rat, 115 days old, and transverse and longitudinal incisions were made in the cortex to as great a depth as possible. Recovery was rapid and without appreciable motor disturbance. She ate alone from the first and seemed practically normal in behavior except for a complete indifference to other animals of the same or opposite sex.

Training in the simple maze was begun 12 days after the operation. The habit of going to the right was perfected in fifty trials. She had, apparently, an initial preference for the right side of the maze. Training to break up this and to establish the habit of going to the left was then started and one hundred and twenty trials were required before ten successive errorless trials were made. The records of time and errors are given in table 2.

TABLE 2

Rate of learning for rat described in experiment 36

\begin{tabular}{|c|c|c|c|c|c|}
\hline \multicolumn{2}{|c|}{ TO RIGHT } & \multicolumn{4}{|c|}{ TO LEFT } \\
\hline Time & Errora & Tume & Errors & Time & Errors \\
\hline 86.0 & 0 & 1370 & 6 & 270 & 3 \\
\hline 97.2 & 2 & 29.0 & 1 & 53.0 & 5 \\
\hline 29.0 & 0 & 35.0 & 3 & 43.0 & 3 \\
\hline 76.2 & 2 & 65.5 & 2 & 37.0 & 1 \\
\hline 620 & 1 & 165 & 2 & 17.0 & 1 \\
\hline 52.0 & 2 & 185 & 1 & 215 & 1 \\
\hline 51.0 & 2 & 310 & 4 & 125 & 1 \\
\hline 263.0 & 3 & 34.0 & 3 & 23.0 & 1 \\
\hline 19.0 & 0 & 125 & 1 & 205 & 2 \\
\hline \multirow[t]{3}{*}{125} & 0 & 420 & 4 & 23.0 & 1 \\
\hline & & 245 & 2 & 9.5 & 0 \\
\hline & & 150 & 0 & 8.5 & 0 \\
\hline
\end{tabular}

The rat was autopsied 40 days after the operation. Microscopical examination of the brain shows (plates I and II, fig. 36): 
Right hemisphere: Destruction of the entire corpus callosum including the knce and all cortical tissue above it and above the hippocampus. A transverse lesion extends laterad from the anterior end of the lateral ventricle along the forceps of the corpus callosum, through the external capsule to the cortex and ventrad to the cerebral peduncle. The fornix is severed with a slight injury to the adjacent thalamus. The lateral ventricle is much enlarged but the corpus striatum is seemingly intact.

Left hemisphere. The corpus callosum is destroyed as on the right with absorption of all cortical tissue above its level. There is a diagonal lesion from the anterior horn of the lateral ventricle to the base of the olfactory lobe, probably involving all the cortex laterad to it. Fornix destroyed and lateral ventricle enlarged until it occupies half of the horizontal area of the lobe. Corpus striatum and thalamus nearly completely destroyed.

The animal shows destruction of the antero-dorsal half of the cerebrum without marked loss in ability to form simple habits.

Experiment 37. A transverse opening, 11 by $6 \mathrm{~mm}$. was made in the calvarium of a large male, 200 days old, just back of the frontal-parietal suture and through it a transverse frontal and longitudinal temporal incisions were made through the cortex, followed by great hemorrhage. Killed 30 days after operation.

The animal recovered quickly, moving about and reacting to other animals within four days after the operation. He was fed by hand for the first four days, then learned to find food for himself but would not eat with the experimenter near. An abscess developed on his neck (infection of the cerebral glands) but cleared up in 20 days. He showed fewer effects of the operation than any other rat in this group, being the only one which showed any responses to other animals. This did not extend to normal sexual reactions.

Training in the simple maze was begun twelve days after the operation. At this time the animal showed no motor disturbance and was normal in his reactions to the experimenter. $\mathrm{He}$ was first trained to go to the right in the maze and required fifty trials for learning. He was then required to go to the left 
for food and again learned in fifty trials. The average time required and the total number of errors made in successive groups of five trials are given in table 3 .

Microscopical examination of the brain showed (plate II, fig. 37):

TABLE 3

Rate of learning for the rat described in experiment $\$ 7$

\begin{tabular}{c|c|c|c|c|c|c|c}
\hline \multicolumn{3}{c|}{ To Riger } & \multicolumn{5}{c}{ TO LEFT } \\
\hline Time & Errors & Time & Errors & Time & Errors & Time & Errors \\
\hline seconds & & seconds & & seconds & & seconds & \\
143.0 & 4 & 9.5 & 0 & 31.0 & 4 & 11.0 & 0 \\
143.0 & 4 & 14.0 & 1 & 175 & 1 & 12.0 & 0 \\
150 & 0 & 14.5 & 1 & 160 & 2 & 210 & 1 \\
420 & 4 & 8.0 & 0 & 185 & 1 & 19.5 & 0 \\
19.0 & 1 & 11.0 & 0 & 155 & 2 & 12.0 & 0 \\
\hline
\end{tabular}

Right hemisphere. Destruction of the greater part of the convexity of the cortex from the occipital portion of the corpus callosum to the knee, involving the greater part of the corpus callosum and exposing the lateral ventricle and extending around the anterior face of the caudate nucleus to the cortex, separating the anterior pole to the level of the olfactory fibers. The fibers of the anterior pole have been absorbed, leaving a large cyst. The longitudinal incision extends backward from the transverse lesion to the middle of the caudate nucleus, then along the course of its fibers, through the external capsule to the cortex, producing, apparently, very little destruction.

Left hemisphere. The lesion on the dorsal convexity is similar to that on the right. The transverse lesion passes just in front of the knee of the corpus callosum and diagonally forward to the base of the olfactory lobe, severing the entire anterior pole to the level of the olfactory tracts. There is invasion of the anterior end of the caudate nucleus by hemorrhage. The longitudinal incision seems to have passed along in the lateral ventricle and to have done little damage. There is an extensive superficial lesion extending over the occipital lobe. 
- Experiment 38. Transverse frontal and longitudinal incisions were made in the cerebral cortex of an old male rat, through a circular trephine hole $8 \mathrm{~mm}$. in diameter. After the operation he was very weak and emaciated rapidly. He was fed by hand for five days, then recovered the ability to eat alone. From the day after the operation he showed a pronounced spasticity of the left side, carrying his head rotated about 60 degrees to the right and walking with the left hind leg extended stiffly and only the tips of the toes set down on the ground. During the first few days he fell over at every third or fourth step and always made a complete rotation to the right in getting to his feet again, his behavior resembling that of an animal after unilateral destruction of the semicircular canals.

In the cage the animal was much more restless than any of the others in the group. He ran almost constantly around an oval path, bounded by the sides of the cage, and always in the same direction, clock-wise. On one day, 35 days after the operation, his activity was observed nearly continuously for 12 hours. During this time he ran around the same path at an average rate of twenty revolutions per minute, with a total of not more than one hour's interruption for rest and eating; a total distance of not less than seven miles: During the 40 days that he was kept under observation he showed very little improvement in motor control beyond that acquired in the first week after operation.

Habit formation. Training in the simple maze was begun 12 days after the operation. He was active, although his movements were very badly coördinated. On the first trial in the maze each day he had great difficulty in walking and his first passage of the central alley was usually a series of somersaults. After the first trial coördination was usually better. After sixty to seventy trials in the maze he learned to traverse it with a few falls but this was accomplished by supporting himself against the sides of the alleys and not by improvement in walking in a straight line. He always had great difficulty in turning around to his left and when he finally learned to go to the food in the left alley of the maze he accomplished 
the turn at the end of the central alley by holding to the end of the partition with both left feet and pushing his body around with the right.

He learned to turn to the right for food after forty trials. The food was then placed in the left alley. The previous habit of turning to the right, reinforced by his motor difficulty in turning to the left made the new habit very difficult for him to acquire and eighty trials were required before he made ten in succession without error. The records of time and errors are given in table 4.

TABLE 4

Rate of learning for rat described in experiment 38

\begin{tabular}{r|r|r|r|r|r}
\hline \multicolumn{2}{c|}{ To R1gat } & \multicolumn{5}{|c}{ To LEFT } \\
\hline Time & Errors & Time & Errors & Tume & Errors \\
\hline 4860 & 1 & 6150 & 100 & 3320 & 30 \\
530 & 2 & 55.0 & 12 & 680 & 6 \\
302.0 & 5 & 2165 & 41 & 580 & 7 \\
45.0 & 1 & 440 & 35 & 19.0 & 0 \\
590 & 2 & 1410 & 12 & 190 & 1 \\
1950 & 0 & 860 & 25 & 20.0 & 2 \\
17.5 & 0 & 383.0 & 91 & 15.0 & 2 \\
14.5 & 1 & 1120 & 20 & 115 & 0 \\
& & 4080 & 31 & 100 & 0 \\
\hline
\end{tabular}

He was killed 40 days after the operation. A small abscess filled with pus was found over the cranial opening but did not extend into the cortical tissues. There was a deep pit in the cortex, completely exposing the lateral and third ventricles. Microscopic examination showed a complete destruction of the convexity of the cortex including the whole of the corpus callosum to the knee (plates I and II, fig. 38). The lesion extends from just behind the corpus callosum diagonally forward to the base of the olfactory lobes, separating the entire frontal pole on either side. The longitudinal incisions extending down over the temporal and orbital surfaces of the cortex to the level of the ventricles with degeneration of neighboring areas. The right corpus striatum is degenerated and infiltrated by large blood 
vessels. The right half of the fornix is severed and there is an extensive clot filling the third ventricle.

There was in this animal a destruction of fully half the cortical tissue, including the frontal pole and nearly all of the dorsal convexity and embracing all of the excitable area and the area described as motor by the histologists; degeneration of the right corpus striatum and fornix; permanent spasticity confined to the left side; no loss of learning ability beyond that due to motor incoördination.

Experiment 39. Transverse frontal and longitudinal incisions were made in the cortex of a small male rat, 126 days old. He was very weak after the operation and grew emaciated rapidly. A hemiparesis appeared immediately after the operation, giving him some difficulty in walking and making it impossible for him to sit up on his hind feet. In the home cage or in the maze when his nose came in contact with the food he at once swung his head to the left, away from the food and against the side of the food dish, which he then gnawed. In order to eat without constant help he had to be placed in a large dish of food. He then usually twisted his head around to the left until his nose was under his left hind leg and ate in that position, gradually straightening out if left to himself. This behavior persisted until the animal was killed, twelve weeks after the operation. During the first three weeks after the operation he had an almost constant erection of the penis and masturbated at frequent intervals. There was a gradual recovery from this but a seeming deterioration in other respects as he became more and more inactive and stuporous.

He was trained to go to the right in the simple maze 11 days after the operation. His paresis made it easier for him to turn to the left and he showed little improvement in accuracy after two hundred trials. The passage-way to the left was then blocked and he was given one hundred trials with only the direct way to the food open. He soon ceased to pause at the blocked entry and ran directly to the food, but when the left passage was again opened he at once entered it and did no better than before. In all, four hundred and fifty trials were given but he only once made five successive trials without error. An examina- 
tion of the records of the first two hundred trials (table 5) shows, however, that he at first made some improvement both in time and in the number of errors and that this improvement was permanent. This is evidence for learning, though of a simple type. In the later part of training he developed a stereotyped reaction to the maze which must be classed as a habit, though it did not contribute to the getting of food. In the trials, day after day, he would first turn into the entrance of the right alley, advance for twice his body-length, then whirl about quickly, run to the

TABLE 5

Rate of learning in rat described in experiment 39

To right

\begin{tabular}{|c|c|c|c|c|c|}
\hline THE & ERROAS & TrME & ERRORS & TINE & ERRORS \\
\hline 149.0 & 3 & 195 & 2 & 630 & 8 \\
\hline 159.0 & 6 & 25.0 & 3 & 390 & 2 \\
\hline 880 & 4 & 620 & 2 & 48.0 & 6 \\
\hline 111.0 & 5 & 470 & 1 & 370 & 6 \\
\hline 1110 & 7 & 600 & 6 & 28.0 & 1 \\
\hline 99.0 & 6 & 28.0 & 2 & 190 & 0 \\
\hline 70.0 & 4 & 66.5 & 7 & 690 & 8 \\
\hline 95.0 & 6 & 440 & 3 & 76.0 & 5 \\
\hline 96.0 & 6 & 480 & 5 & 31.0 & 3 \\
\hline 580 & 3 & 370 & 3 & 230 & 2 \\
\hline 750 & 6 & 37.0 & 3 & 490 & 4 \\
\hline 59.0 & 5 & 79.0 & 3 & 19.0 & 1 \\
\hline 65.0 & 5 & 590 & 3 & 290 & 4 \\
\hline 62.0 & 2 & 61.0 & 4 & 33.0 & 4 \\
\hline
\end{tabular}

end of the left alley, turn back to the right alley and go directly to the food. Records of time and errors for the first two hundred trials are given in table 5 .

The rat was killed 71 days after the operation. Microscopical examination of the brain showed (plates I and II, fig. 39):

Right hemisphere. There is a destruction of tissue over the dorsal convexity of the cortex down to and including the corpus callosum. There is transverse lesion extending diagonally forward just behind the knee of the corpus callosum to the base of the olfactory bulb, completely cutting off the frontal pole. The fornix and gyrus dentatus are completely destroyed. The cor- 
pus striatum is cut through in sagittal section for its full length and the lesion filled by a large clot which extends down into the cerebral peduncle, cutting through its fibers obliquely. The anterior portion of the caudate nucleus is replaced by a clot, the remainder is much shrunken. The antero-lateral surface of the thalamus shows indications of degeneration.

Left hemisphere. There is destruction of all tissues above and including the corpus callosum. A transverse lesion extends diagonally from behind the knee of the corpus callosum to the base of the olfactory bulb, severing the anterior pole. The lateral ventricle is collapsed and all the cortex laterad to it is replaced by scar tissue. The external capsule lies free in a cyst laterad to the corpus striatum and, in the occipital lobe, is replaced by a large cyst. The corpus striatum is degenerated. The fornix is largely destroyed. The thalamus is intact.

In this animal the destruction of all the cortex above and in front of the corpus callosum and laterad to the left lateral ventricle with partial degeneration of the right and complete degeneration of the left caudate nuclei, destruction of the fornix and injury to the thalamus on the right was followed by inability to solve the simple maze but did not preclude the formation of simple habits as evidenced by the gradual appearance of stereotyped modes of response to the maze.

The course of learning in these different animals is compared with the average of normal individuals trained under the same conditions in figure 13. The animals described in experiments 35 and 37 were apparently normal in behavior and learned in about the same amount of practice as is required by normal rats. The animals in experiments 36 and 38 learned to go to the right quite readily but had a great deal of difficulty in readjusting to the problem when they were required to overcome the first habit and learn to turn to the left. The rat in experiment 39 was unable to learn the problem in more than three hundred trials. However, even this animal showed marked improvement in the time required for running the maze during the early part of practice. In experiments 38 and 39 a part of the difficulty experienced by the animals was clearly due to a persistent hemi- 
paresis which made it easier to turn to one side than to the other. They did show, however, some indications of abnormality in learning not due to the motor difficulty. The development of stereotyped errors in experiment number 39 and the large number of errors of the same type made by the rat in experiment

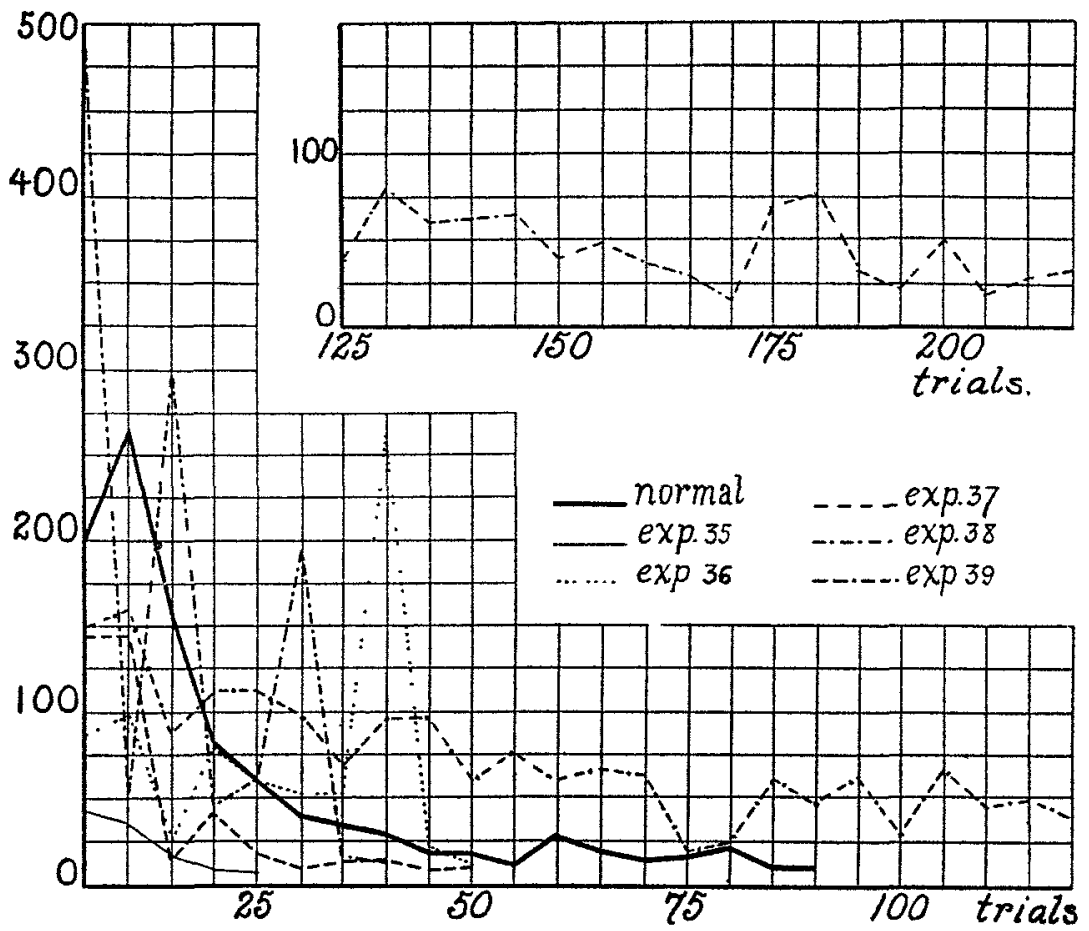

Fig. 13. A Comparison of the Rlate of Learning the Simple Maze by Normal Amimals and by Animals After Destruction of the antrerior and Dorsal Surfaces of the Cortex

38 in the second training test (table 4) are without parallel in the behavior of normal animals. They indicate, perhaps, an abnormal predominance of kinesthetic-motor chain reflexes and a difficulty in inhibiting them in new situations. This is suggestive of the perseverations sometimes seen in human defectives. 
In every one of the animals clear evidence of some degree of habit-formation was obtained. Whether or not the possible complexity of habit was limited by the destruction in these cases was not definitely determined by the experiments. No attempt was made to train the animals in more difficult tasks and until experiments can be carried out on a more extensive scale we can conclude only that somewhat more than the anterior half of the cerebral cortex in the white rat (fig. 14) is unnecessary for the formation of simple habits.

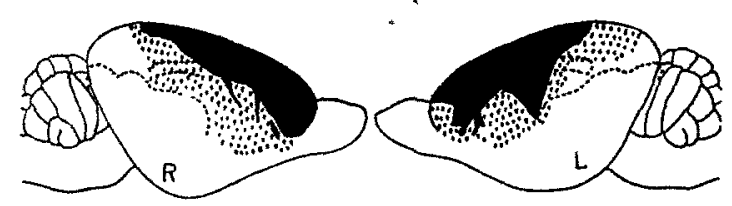

Fig. 14. The Total Extent of the Combined Lesions in the Animals Which Learned the Stmple Maze After Operation. Series V

\section{Discussion}

To the destruction of what structural elements may the loss of the plane-box habit be ascribed, and to what the retention in the cases of partial destruction? The lesions in many cases involve the motor area and the loss of the habitual reaction might be considered as primarily the result of the motor disturbances arising from injury to this region. However, such facts as we have at hand concerning the motor area in the rat do not support this view.

The cyto- and myelino-architecture of the brain of the rat has not been worked out but Isenschmid (7) has given a full account of the arrangement and composition of the cell-layers of the different regions of the cortex of the mouse and the similarity of the brains of the two species is probably sufficient to justify the application of his results to the rat. He finds three principle areas, fronto-medial, dorso-lateral, and sub-occipital, distinguished by the relative thickness of the cell-layers and the size of the elements, and within these distinguishes a number of subordinate areas. Those which have come within the scope of the present experiments are shown in figure 15. 
The majority of writers agree that there is a frontal field, variously located in the region $l$ which has not the characteristics of the motor areas, but no statements are made as to its relation to the frontal lobes of higher mammals. The stimulation experiments which we have carried out indicate that even the extreme pole of the cortex is excitable, that there is no silent area corresponding to the frontal lobes of higher mammals, but the small size of the brain and the difficulty of preventing some spreading of the current would make it difficult to detect such an area if it existed.

There is no experimental evidence concerning the function of these fields, although a part has been interpreted as motor,

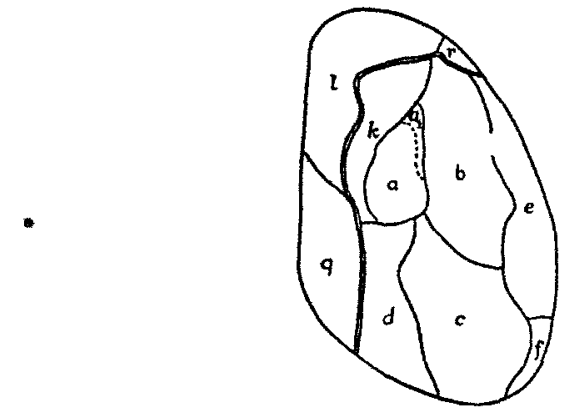

Fig. 15. The Chief Cytoarchitectural Areas of the Brain of the Mouse. AFTER IsENSCHMind

another as sensori-motor. According to Isenschmid, who has summarized the literature of this subject the area described as motor differs considerably in the descriptions of different authors.

Upon purely histological grounds Cajal includes an area extending over $a, a_{l}$, and $b$, in figure 15 . Döllken (8) includes the areas $l, k, a, a_{l}, b$, and the anterior portions of $q$ and $d$ Brodmann (9) includes $k$ and a part of field $l$.

Without physiological verification conclusions as to the function of histologically differentiated parts can have little value. The stimulable area has been found to correspond most closely to the anatomical field described by Döllken. The excitable areas thus far determined are shown in figure 16 . They em- 
brace the entire frontal pole and the areas $l, k, a, a_{l}$, and a part of the anterior portions of $q$ and $d$ (fig. 15) including most of the area described by Döllken but not extending so far over the parietal surface as his figures indicate.

In the operative experiments this entire motor area was frequently destroyed completely without serious interference with the animal's ability to form kinesthetic-motor habits.

After purely cortical destruction we have never found any motor disturbance which has persisted for as much as eighteen hours after the operation; in particular there is no indication of localized disturbances in the front or hind limbs resulting from

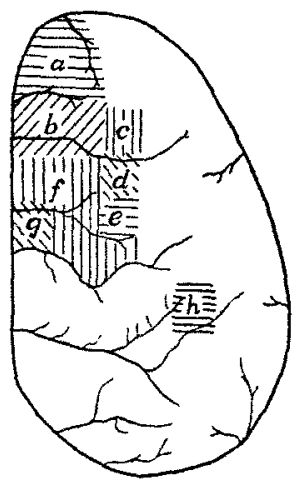

Fig. 16. The Distribotion of the Stimulable Areas in the Brain of THE RAT

the destruction of corresponding regions of the stimulable area. In those cases where motor disturbances were observed there appears to have been always a very extensive injury to the corpus striatum. (The material is being reëxamined with reference to this point.) It seems clear, then, that the loss of the habits was not due directly to motor paralysis.

In experiments $27,30,32$, and 33 there was destruction of the frontal pole including at most only the stimulable area for the head and neck and, with this, complete loss of the habit. So it seems almost certain that in these cases the loss of the habit was due to the interruption of some other cortical reflex pathways than those included in the excitable area. The effects of 
the operations upon retention can not be looked upon as the result of a motor insufficiency, nor, probably, as primarily the result of the destruction of the excitable area.

Previous work (10) on the function of the frontal portion of the cortex' in higher mammals (cat and monkey) has given evidence that this part of the cortex is normally utilized in habit-formation, but that in its absence some other portion of the brain may usurp its function. Further, there is evidence that when the habits have been practiced for a long time by normal animals the preservation of the frontal lobes is no longer a condition of their correct functioning; they come to be carried out, probably, at a lower level of nervous organization. It was the primary purpose of this study to determine the amount of practice necessary for retention of a habit after ablation of the part of the cortex originally functional in its performance. This purpose has been largely defeated by the great variation in the extent of destruction in different animals. The results, however, verify for the rat the findings for higher mammals and suggest some additional possibilities of interest. The experiments of series I, II, and V indicate either that very simple habits such as that of turning in the simple maze may be acquired by normal animals without the utilization of the frontal portion of the cortex at any time during learning, or that the cortex very rapidly ceases to function in the performance of the habit. There is a little evidence, noted in the first paper, that the animals of series I which have been long overtrained retained the habit a little more perfectly than those which were trained to perfect performance. The irregular conditions of training incident to the use of the animals in other experiments and the great variation in the extent of the lesions makes the justice of such a conclusion questionable.

In the more complex habit of the inclined plane box the presence of some portion of the frontal pole is evidently a condition for the performance of the habit where this has been acquired with the frontal pole intact. Again, owing to the small number of animals tested and the variation in extent of the lesions the data on the relation of the amount of practice to the functions 
of the cortex is inadequate. From experiments 29, 31, and 33 in which animals were overtrained it seems that an amount of overtraining equal to three or four times that required for learning is insufficient to reduce the habit to lower brain levels. The difference in the complexity of the maze and inclined-plane box habits and the apparent failure of the latter to be reduced to subcortical levels within the limits of these experiments suggest that the amount of practice necessary for the assumption of the cortical functions by subcortical ganglia is proportional to the complexity of the habit. Until further evidence is accumulated this can not be considered more than a probable assumption.

The data presented in section IV shows that complete destruction of the frontal pole results in the loss of the plane-box habit, whereas the loss of the temporal and parietal regions is without effect upon the habit. This indicates that conduction pathways involved in the performance of the habit pass through the frontal pole, but an attempt to localize these more accurately brings to light a complexity of function which has not before been suggested. Partial destruction of the frontal pole did not always result in the loss of the habit. An attempt to find a correlation between the part destroyed and the retention or loss of the habit revealed the further fact that no single part of the frontal pole escaped destruction in all the animals which retained the habit (fig. 14). It seems then that for retention some part of the frontal pole must be preserved but no particular part seems necessary. This is, perhaps, what might be expected if we abandon the purely diagrammatic concept of the reflex cortical arc as a single chain of neurones and consider that for the performance of even a simple movement a number of such arcs are required. With a vast number involved in complex habitual acts, it is very improbable that all would be projected on a restricted area of the cortex; the experimental results suggest rather that in their cortical relations these arcs are widely distributed over the frontal pole so that a partial lesion results in only the partial destruction of the ares involved in the performance of any simple act.

The experiments of series $\mathrm{V}$ have shown that the rat may form 
simple habits after the complete destruction of all the cortex of the frontal, temporal, and parietal regions and the greater part of that on the orbital surfaces. This includes all the regions to which the function of habit formation has been ascribed and leaves only those which have been thought to have visual, auditory, and olfactory functions. The destruction of cortical tissue has not been extensive enough to prove that learning may take place wholly at the level of the sub-cortical centers but the evidence at hand is sufficient to justify more extensive experiments upon this point. The ability of the animals to form habits after the loss of those parts of the brain which are normally used in learning, the reëstablishment of motor control after the loss of the stimulable area of the cortex and of the corpus striatum, and the seeming equipotentiality of the different parts of the frontal pole in the functioning of complex habits go far toward establishing the complete functional interchangability of all parts of the cerebral cortex.

\section{SUMMARY}

Rats were trained after destruction of various parts of the cerebral cortex including the frontal, temporal, parietal, and a large part of the orbital surfaces and the influence of the cerebral destruction upon their ability to form and retain kinestheticmotor habits was tested. It was found that:

F. The habit of turning correctly in the simple maze may be retained after the destruction of any part or all of the cortex lying in front of and above the knee of the corpus callosum and after the destruction of any part of the temporal and parietal regions.

2. The maze-habit may be acquired after the destruction of all the cortex included within these areas, and after the destruction of one, perhaps both, of the striate nuclei.

3 . The more complex habits involved in opening the inclinedplane box are retained after destruction of the temporal regions of the cortex.

4. The complete destruction of the frontal regions of the cortex results in the loss of the inclined-plane box habit. 
5. The partial destruction of the frontal region does not abolish this habit.

6. So long as the destruction of the frontal pole is not complete the habit is retained, apparently irrespective of what part of the frontal region has been destroyed.

7. No marked motor disturbances appear after the complete destruction of the strmulable areas of the cortex but in certain cases marked hemiparesis seemed to result from the destruction of the corpus striatum.

\section{REFERENัCES}

(1) This journal, 1917, i, 1-15.

(2) Watson, J. B.: Behavior, New York, 1914.

(3) Franz, S. I.: On the functions of the cerebrum. American Journal of Physiol., 1902, viii, 1-22. Archives of Psychol., New York, 1907, no. $2,1-64$.

(4) BuRneTt, T. C.: Some observations on decerebrate frogs with especial reference to the formation of associations. Amer. J. of Physiol. $1912, \mathrm{xxx}, 80-87$.

(5) Goutz, F.: Der Hund ohne Grosshirn. Arch. f. d. ges. Physiol., 1892, li, 570-615.

(6) Rothman, M.: Demonstration des Hundes ohne Grosshirn. (Ber. über d. V. Kongress f. exper. Psychol.) Leipzig, Barth, 1912, pp. 256-260.

(7) Isenschmid, R.: Zur Kenntnis der Grosshirnrinde der Maus. Abh. d. Königl. Preuss. Akad. d. Wiss., 1911, 1-46.

(8) Döllken, I.: Beitrüge zur Entwickelung des Saügergehirns. Lage und Ausdehnung des Bewegungseentrums der Maus. Neurol. Centbl., 1907, xxvi, 50-59.

(9) Brodman, K.: Vergleichende Lokalisationslehre der Grosshirnrinde. Leipzig, 1909.

(10) Franz, S. I.: Opus cit.

\section{PLATE I}

Fxa. 22. Serial horizontal sections, $1.6 \mathrm{~mm}$. apart, of the brain of the rat described in experiment 22 . The positions of the structures used as reference points in the descriptions of the lesions are noted on the figures. C.ex., external capsule; c.st., corpus stratium; $f$., fornix; f.c., forceps of the corpus callosum; $h$., hippocampus; n.c., anterior olfactory nucleus; n.l., lateral thalamic nucleus; o., base of olfactory bulb; s.p., septum pellucidum; v.l., lateral ventricle.

Fia. 38. Serial sections of the brain of the rat described in experiment 38 . The method of reconstruction is shown in this and plate II, figure 38 .

Fro. 36. Horizontal section through the brain of the rat described in experiment 36 .

Fra. 39. Horizontal section of the brain of the rat described in experiment 39 , showing a probable complete destruction of the left hemisphere. 
是
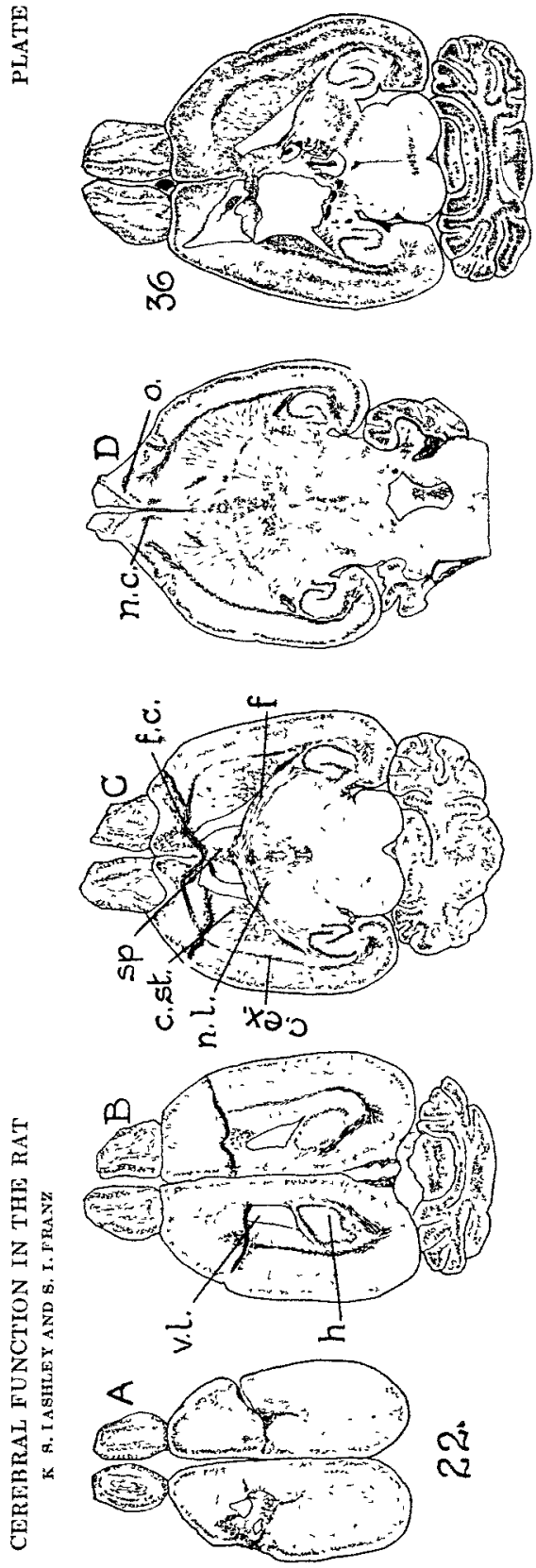
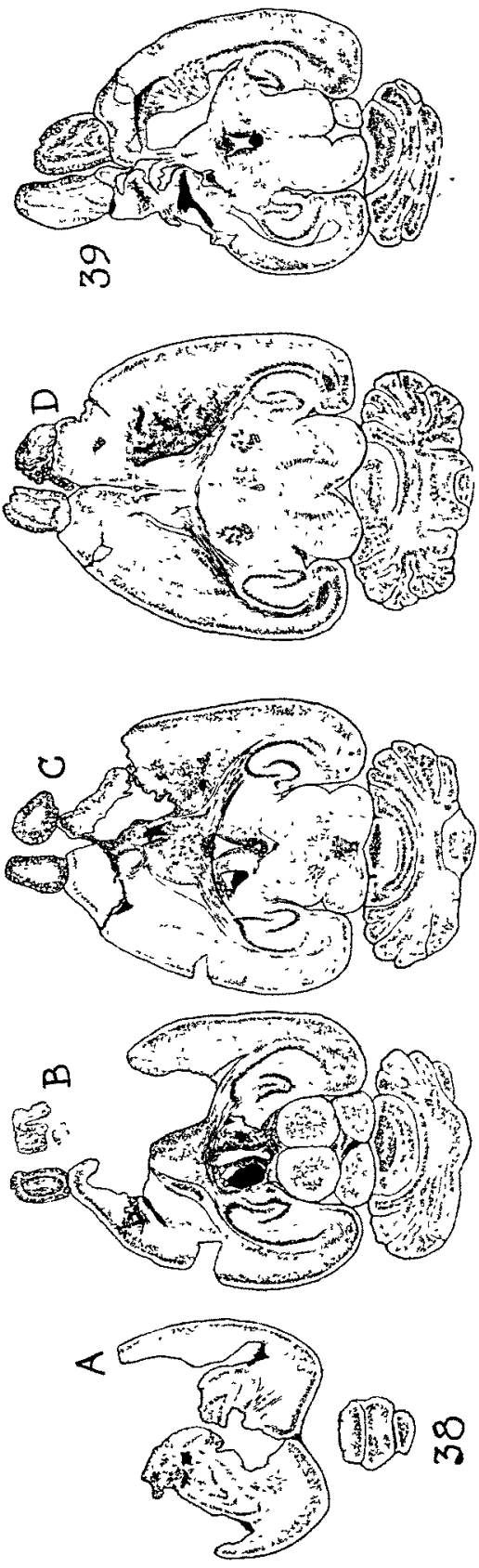


\section{PLATE II}

Fuas. 1 to 14. The extent of the lesions in anmals which retained the habit of the simple maze after cercbral destruction. The numbers of the figures correspond to the numbers of the experiments under which the animals are described. In figures 10,11 , and 12 the striated areas show the extent of the second operation.

Fras 34 to 39 . The extent of the lesions in animals which formed simple habits after operation. The solid black areas are those in which the cortex was completely absorbed. The dotted areas are those in which the cortex was probably not functional as a result of the destruction of its descending fibers 


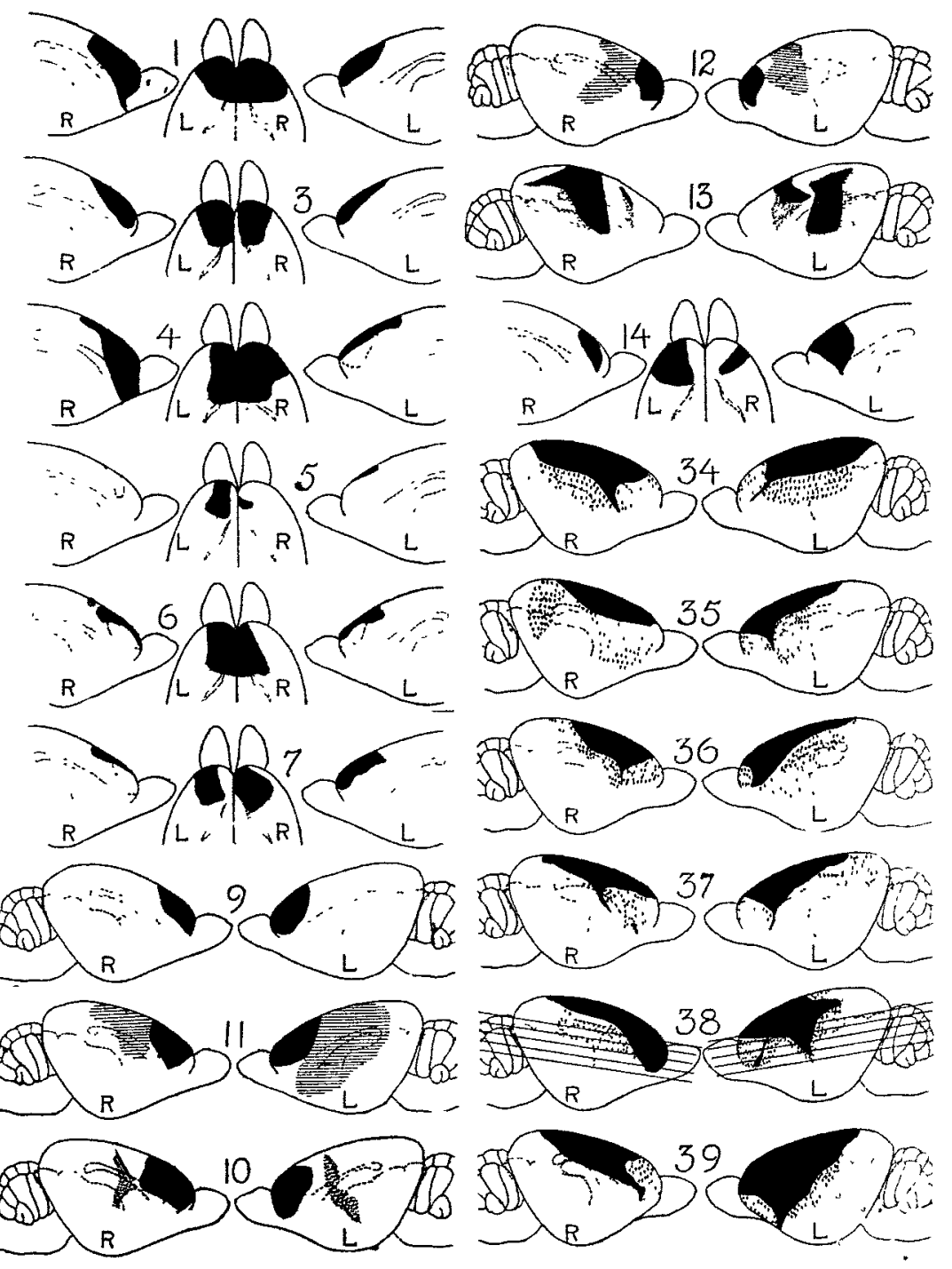




\section{PLATE III}

Fig. 17. Lesion in the control animal in which there was no operation on the brain.

Figs. 18 and 19. Lesions in the control animals after operation on the temporal lobes.

Figs. 20 to 24 . The extent of the lesions in the animals which retained the inclined-plane box habit after operation.

Figs 25 and 26. The extent of the lesion in the anmals which showed a doubtful retention of the habit.

Figs 27 to 33. The extent of the lesion in the animals which lost the inclinedplane box habit after operation. 


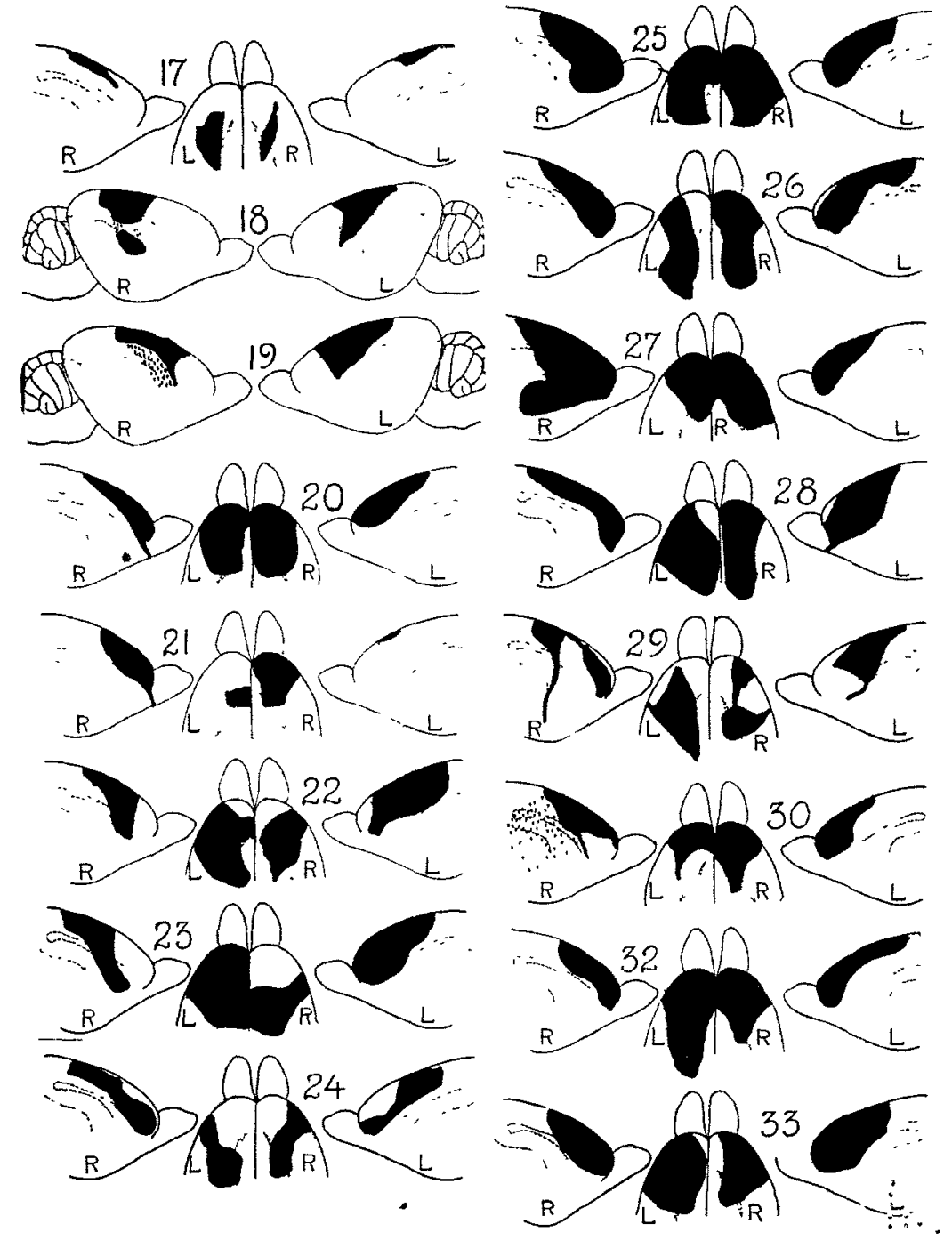

